\title{
LOURDES. CENTRO DE PEREGRINACIÓN, VOLUNTARIADO Y TURISMO
}

Sagrario de Benito Rodríguez

Universidad CEU San Pablo de Madrid

\begin{abstract}
Resumen: Intentamos mostrar qué es Lourdes y por qué se viene a este lugar. Un paseo por sus signos y edificaciones permite entender que los turistas, visitantes, peregrinos y voluntarios que aquí llegan de todos los rincones del mundo son testigos de esperanza y caridad. Un paseo por Bartrès amplía la visión del camino recorrido por Bernardita como primera peregrina. Esta ciudad mariana como centro internacional de peregrinación y voluntariado goza de una riqueza espiritual, artística, cultural, natural, paisajística y turística. Esta riqueza vivida y compartida desde la generosidad y gratuidad asegura la formación integral del voluntario consolidando su formación humana a la vez que perfecciona la Lengua Francesa.

Palabras clave: Lourdes, centro de peregrinación, voluntariado, turismo, santuario, naturaleza, formación integral, lengua francesa.
\end{abstract}

\section{Resumo: Lourdes. Centro de peregrinación, voluntariado e turismo}

Intentamos mostrar que é Lourdes e por que se vén a este lugar. Un paseo polos seus signos e edificacións permite entender que os turistas, visitantes, peregrinos e voluntarios que aquí chegan de todos os recantos do mundo son testemuñas de esperanza e caridade. Un paseo por Bartrès amplía a visión do camiño percorrido por Bernadette como primeira peregrina. Esta cidade mariana como centro internacional de peregrinación e voluntariado goza dunha riqueza espiritual, artística, cultural, natural, paisaxística e turística. Esta riqueza vivida e compartida dende a xenerosidade e a gratuidade asegura a formación integral do voluntario consolidando a súa formación humana á vez que perfecciona a lingua francesa.

Palabras clave: Lourdes, centro de peregrinación, voluntariado, turismo, santuario, natureza, formación integral, lingua francesa.

Abstract: Lourdes. Pilgrim, volunteering and tourist centre 
Our intention is to explain what Lourdes is and why people come to visit it. A walk through its symbols and buildings allows us to understand that the tourists, visitors, pilgrims and volunteers who come here from all four corners of the world are witnesses to hope and charity. A walk through Bartrès widens the vision of the route taken by Bernardette as the first pilgrim. This Mariana city, as an international centre for pilgrims and volunteers, enjoys a spiritual, artistic, cultural, natural, landscape and tourist richness. This richness, lived and shared on the basis of generosity and gratitude, ensures the comprehensive training of the volunteers, strengthening their human development at the same time as perfecting their French.

Key words: Lourdes, centre for pilgrimages, volunteering, tourism, sanctuary, nature, comprehensive training, French language.

\section{QUÉ ES LOURDES Y POR QUÉ SE VIENE A ESTE LUGAR.}

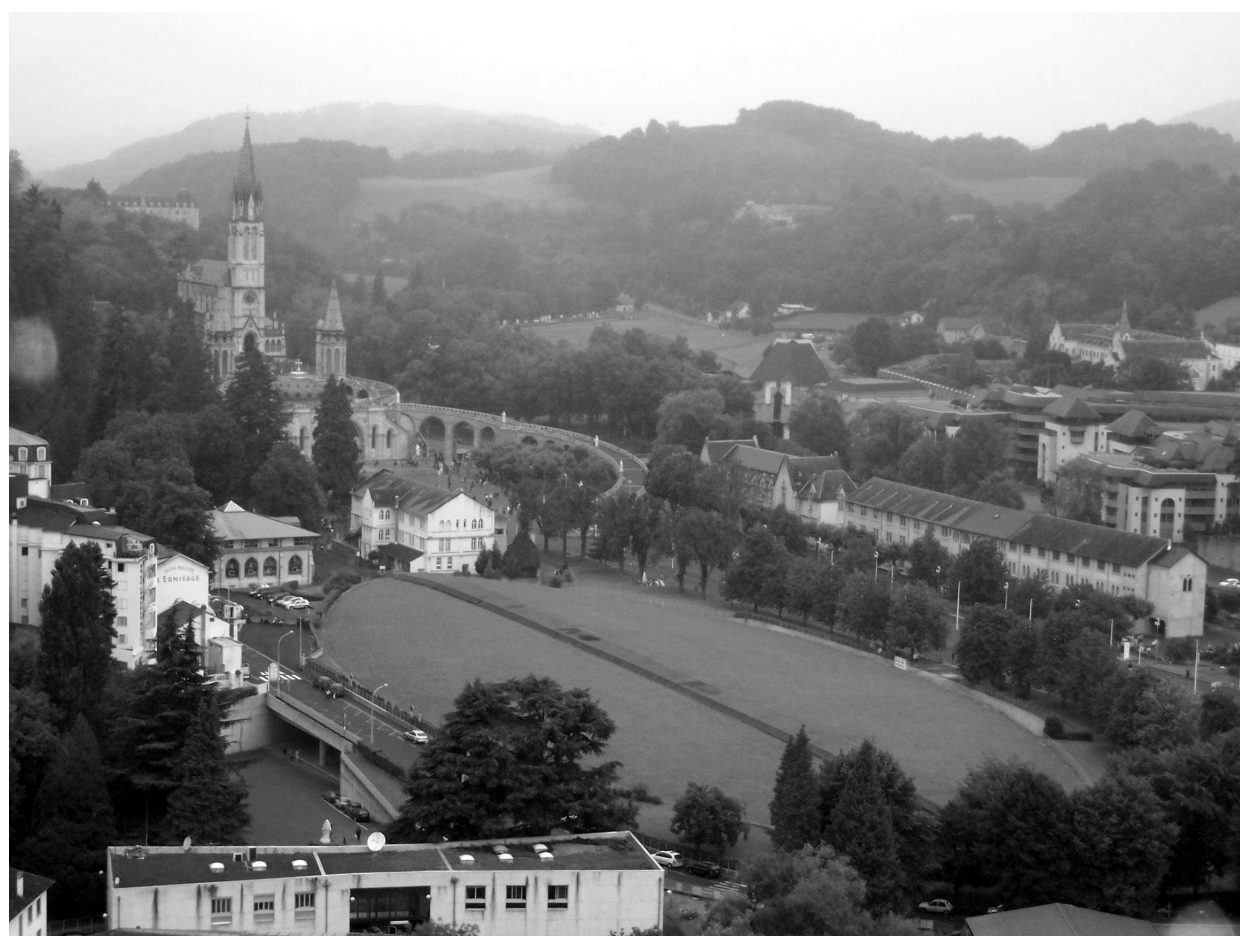

Foto 1. Vista de las edificaciones en Los Santuarios. Bajo el césped en forma de barca y de pez se encuentra la Basílica subterránea San Pío X y al fondo la montaña del Valle Pirenaico.

\subsection{LA FIGURA DE BERNARDITA SOUBIROUS.}

En Lourdes, la Virgen habló a una chica de 14 años muy pobre y enferma, padecía asma. Tenía esta adolescente una salud delicada, y físicamente era muy poquita cosa. La niña se llamaba Bernardita y vivía en los ALTOS PIRINEOS rodeada de montañas, ríos, arroyos, ovejas y vacas; un entorno ideal, un lugar extraordinario que nos brinda el sosiego transmitido por el paisaje de la montaña pirenaica. 
Bernardita, pobre y enferma, no tenía una chimenea llena de leña que calentara el hogar durante las largas épocas de lluvia. La familia no tenía leña ni dinero, pero no siempre fue así. Bernardita era hija del amor, sus padres se casaron por amor y vivía junto a sus hermanos y hermanas en un ambiente de mucho cariño y de oración. Su padre Francisco Soubirous era molinero y junto a María Luisa Casterot, la madre de Bernardita, mantenían un molino de agua en el centro del pueblo, muy próspero, es el MOLINO DE BOLY. Bernardita nació un 7 de enero de 1844 en este hogar lleno de amor y sin ninguna dificultad económica, por eso este molino se llama también el MOLINO DE LA FELICIDAD, actualmente puede visitarse y ver cómo transcurrieron los primeros diez años de su vida. Se llama Bernardita en honor a su tía mayor, la hermana de su madre con quien François debería haberse casado pero que no hizo porque se enamoró de Louise, la hermana pequeña.

Los problemas de dinero fueron viniendo poco a poco hasta dejar a la familia en la calle; los molinos de agua fueron sustituidos por los de luz, el padre se hizo daño en un ojo y no podía trabajar, más tarde fue acusado de robar, en fin, una desgracia tras otra hasta que no tuvieron un tejado donde cobijarse. Tiempo de gran pobreza. Actualmente, en Francia podrían ser considerados como $\mathrm{SDF}^{2}$ y en España podríamos pensar en los sin techo. Gracias a un familiar se les dejó ocupar lo que fue hasta 1824 la prisión del pueblo o CACHOT, un calabozo de unos dieciséis metros cuadrados que servía de cocina, comedor y dormitorio a los seis miembros de la familia Soubirous. Bernardita que había contraído el cólera en 1854 y era asmática vive su enfermedad en una habitación insalubre. Es de esta habitación de dónde se escapa para ir a buscar leña con su hermana pequeña Toinette y una amiga. A escondidas, llegaron a una cueva cerca del río Gave para ver si encontraban ramas secas con las que calentar el humilde hogar. Y fue en esa cueva donde la adolescente empezó a oír y ver a la Virgen. Hoy es lo que se conoce como LA GRUTA, en aquellos años, era una pedazo de roca a las afueras de Lourdes no muy frecuentado salvo por algunos animales como cerdos y ovejas.

Esta situación se vuelve cada vez más dura pero la familia no deja de rezar y de estar unida. Tiempo de sufrimiento, de pobreza y enfermedad. Y es que la felicidad había terminado, la niña ahora era pobre, estaba enferma, era frágil, no sabía leer ni escribir, y la vida en el calabozo, en $L E C A C H O T$ era dura para toda la familia Soubirous. Entonces, Bernardita para ayudar a sus padres y ser una boca menos que alimentar, parte a Bartrès, un pueblo a unos cuatro kilómetros de Lourdes para ocuparse de las ovejas de la Señora Laguës. Se va con la condición de iniciar su formación en la iglesia del pueblo y poder realizar la comunión, sin embargo, el sacerdote abandona el pueblo para ingresar en un monasterio y la Señora Laguës lejos de ayudar a la niña y de enseñarle a escribir y leer en francés, le dice que es tonta, y que nunca hará la comunión, Bernardita es la criada que se ocupa de todo, de la casa, los niños, las ovejas, del campo, estaba tan cansada, débil y se sentía tan desgraciada

2 SDF. Sans Domicile Fixe: Sin techo. 
que un domingo se marchó de esta casa para ir a ver a sus padres a Lourdes y nunca más volvió a ser la criada, pastora, granjera maltratada y ofendida de Bartrès. En Lourdes, todo el mundo sabía que Bernardita era pobre, que estaba enferma y que no sabía leer ni escribir, esta última circunstancia hacía sufrir mucho a la niña pues no podía aprender el catecismo para hacer la Comunión. Pero no dejaba nunca de rezar. En este mismo año de 1857 cuando regresa de Bartrès, su padre es encarcelado acusado de forma injusta de robar harina. En esta situación de desencantamiento, humillación y desesperanza empiezan las Apariciones.

\subsection{LOS MENSAJES DE LA VIRGEN A BERNARDITA}

La Virgen, al acercarse a Bernardita, quiere acercarse a los pobres, a los enfermos de cuerpo, corazón y de alma, a los ignorantes y a los que no han tenido la posibilidad de recibir una educación, una formación, y a todos los que sufren por ello. Cuando empezaron las apariciones nadie la creía, ni siquiera el sacerdote del pueblo, el Párroco Peyramale, de gran estatura y robusto como un oso. Cada vez que veía llegar a Bernardita a su Casa Parroquial y llamar a su puerta, se ponía enfermo, se preguntaba que tontería le diría esta vez. Actualmente, la casa del Párroco Peyramale es la Biblioteca municipal de Lourdes. ¡Cuánto sufrimiento para Bernardita que debía transmitir a este sacerdote los mensajes de la Virgen! En el pueblo, la gente no creía a Bernardita y las mujeres adineradas no entendían como la Virgen podía preferir a una adolescente pobre, miserable, enferma e insignificante como ella. En esta situación, la Virgen se aparece a Bernardita. Pero, ¿Qué se dijeron la Virgen y Bernardita en la GRUTA DE MASSIABELLE? Bernardita tenía 14 años cuando empiezan las apariciones ${ }^{3}$ el 11 de febrero de 1858. La Virgen le habla de sufrimiento, oración y conversión.

Durante las Apariciones, la niña sigue recibiendo críticas de las personas más influyentes de Lourdes, también de algunas autoridades ${ }^{4}$. Incluso el Párroco Peyra-

3 - En la tercera aparición del día 18 de febrero, la Virgen habla por primera vez y le dice:

"Si puede venir a este sitio durante quince dias, y no le prometo ser feliz en este mundo sino en el otro."

- En la octava aparición del miércoles 24 de febrero:

"Penitencia, penitencia por los pecadores" y "bese al suelo para la conversión de los pecadores."

Durante dos apariciones más, la Virgen le dio este mismo mandato, insistió sobre la conversión de los pecadores.

- En la novena aparición del jueves 25 de febrero, la Virgen pidió a Bernardita que hiciera brotar un manantial de agua para que los hombres pudieran no sólo beberla sino lavarse para limpiar los pecados y renovar la fe.

"Ve a beber a la fuente y a lavarte, comerás de esa hierba que crece ahi."

- En las apariciones 13 y 14, del 2 y 3 de marzo respectivamente, la Virgen le pidió a Bernardita que se construyera una Capilla y se fuera en Procesión. Las primeras edificaciones que forman Los Santuarios se edifican sobre la Gruta.

"Ve y di a los sacerdotes que se venga aquí en procesión y se construya una capilla."

- En la aparición 16 del día 25 de marzo, la Virgen le reveló su nombre:

"Yo Soy la Inmaculada Concepción"

4 Después de la sexta aparición del 21 de febrero, el Comisario de Policía Jacomet interroga a Bernardita. En la séptima aparición, en presencia de unas cien personas, acudió el médico para comprobar si se trataba o no de una loca, el Dr. Dozous vio nada fuera de lo normal, fue testigo en la decimoséptima aparición 
male en la decimotercera aparición le dijo a Bernardita que preguntara el nombre a la Señora y que le dijera que hiciese florecer el rosal de LA GRUTA en pleno invierno. Soporta reproches, críticas y amenazas hasta que la Virgen finalmente le dice su nombre veintiún días más tarde, el 25 de marzo, festividad de la Anunciación de María.

Bernardita después de las Apariciones y transmitidos los mensajes de la Virgen, busca refugio en el Hospicio de Lourdes, al lado de las Hermanas de la Caridad y de la mano del sacerdote Peyramale pudo hacer realidad su sueño más querido: hacer la Comunión el 3 de junio de 1858. Y de nuevo, las críticas, la gente decía que no había asistido a los cursos ni seguido la formación adecuada para recibir la comunión y que por lo tanto no debería haberla hecho. Sólo el sacerdote Peyramale podía tener la buena respuesta: Bernardita ha realizado su catequesis durante los seis meses que duraron las 18 apariciones 5 .

Después, decide hacerse religiosa, ingresa en la Orden de las Hermanas de la Caridad, abandona Lourdes y en 1866 con 22 años se va al Convento que éstas tienen en la ciudad de Nevers. Aquí se dedicaría, después de estar al servicio de los demás, a ser enfermera y aquí moriría alejada del mundo y de cualquier publicidad a los 35 años, en 1879. En dicho convento se conserva su cuerpo incorrupto, y puede ser visitado. Bernardita pasa 22 años en Lourdes y 13 años en Nevers.

\subsection{PERFIL DE BERNARDITA + DESEOS DE LA VIRGEN.}

Los mensajes de la Virgen a la niña son una invitación que la Virgen hace a todos los hombres para que vengan a Lourdes. El perfil escogido de la niña es una muestra del amor del Cielo hacia los más desvalidos.

El significado de Lourdes sería que cada persona, identificándose con Bernardita, pudiera, como ella, escuchar a la Madre que le mira y habla como una persona mira y habla a otra persona. Esta identificación y relación es la misma que se establece entre Lourdes y el Cielo a través de cinco signos ${ }^{6}$ :

1. El gentío que se compone de todos los hombres que sin distinción acuden a Lourdes para ponerse frente a la Virgen y orar, llorar, pedir o agradecer. La necesidad de oración explica las peregrinaciones.

2. Los enfermos, los pobres de salud de cuerpo y de mente. La caridad explica el vo-

\footnotetext{
del milagro del cirio que por el viento parecía quemar la mano de Bernardita y pudo él mismo comprobar que nada le había pasado, y entonces creyó y se convirtió. En la novena aparición cuando Bernardita bebe por primera vez del agua que hace manar del suelo y come una hierba que había junto a la fuente, fue interrogada por el procurador Dutour y amenazada con la cárcel si regresaba de nuevo a $L A G R U T A$. También durante la undécima aparición asistió un militar en medio de unas mil personas, el procurador Dutour, que llevó a Bernardita delante del juez de instrucción Ribes para ser interrogada y amenazada con la cárcel, pero ella se mantuvo siempre segura.

5 De febrero a abril de 1858 tuvieron lugar 17 apariciones y la última fue el 16 de Julio, Fiesta de Nuestra Señora del Carmen.

6 Los cinco signos de Lourdes pueden verse en el Museo de Sta. Bernardita. Los libros sobre Lourdes explican estos signos detalladamente así como las páginas Web de Los Santuarios: www.lourdes-france. org y www.lourdes-france.com
} 
luntariado porque dando es como más se recibe.

3. La vela es luz y testimonio de cada hombre en Los Santuarios. Es una prolongación infinita del hombre particular como testigo de esperanza y salvación eterna.

4. El agua como símbolo de purificación y renovación bautismal es un asentamiento en la $f e$ y en su propagación.

5. La roca es la Iglesia fundada por Pedro, cuando el hombre toca y besa la casa de Dios expresa que la considera el refugio donde puede ponerse a salvo.

En su peregrinación a Lourdes, el hombre busca en el refugio de la fe, la caridad y la esperanza.

Para entender lo qué es Lourdes hay que unir el perfil de Bernardita con los mensajes de la Virgen, la personalidad de la niña con los deseos de la Virgen. Cada hombre puede identificarse con alguna de las circunstancias que rodearon a la niña. La identificación y el paralelismo se hacen realidad a través de estos signos que ocu-

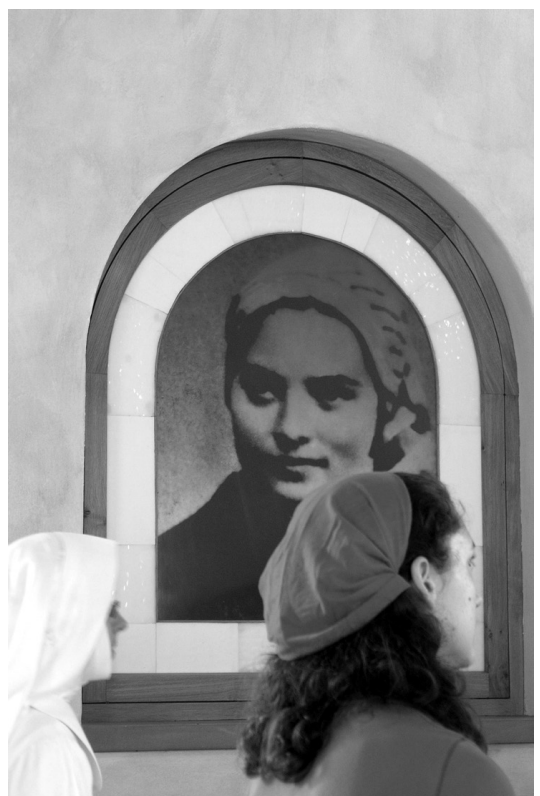

Foto 2. Retrato de Bernardita y voluntarias. pan las diferentes edificaciones de este lugar santo y permiten hablar de Santuario en plural. Cada edificación de LOS SANTUARIOS hace referencia a una de las cualidades de Bernardita y a uno de los deseos de la Virgen. Y es que cada símbolo en cada espacio dice y expresa lo que el hombre de forma callada ha venido a decir.

Después de las Apariciones, Bernardita decía que la Virgen se fijó en ella porque no había en el mundo nadie más pobre ${ }^{8}$. Pero gracias a esta pobreza, la adolescente fue a buscar leña y la Virgen se le apareció dieciocho veces. También decía que no sabía leer ni escribir francés, sólo hablaba el dialecto de la zona de $L A B I G O R R E$, el bigurdan, pero gracias a este hecho, la niña podía comunicarse con el sencillo lenguaje del corazón. Por eso, a la pregunta: ¿En qué lengua se hablaron la Virgen y Bernardita? Se responde que se hablaron me-

7 LOS SANTUARIOS hacen referencia a todos los edificios que componen este lugar santo. Más tarde, se ofrece una explicación de estas diferentes edificaciones.

8 A Bernadette le hacía sufrir mucho su ignorancia, ella misma dice que la Virgen la eligió porque no había nadie más ignorante que ella: “... si la Sainte Vierge m'a choisie c'est parce que j'étais la plus ignorante" (Archives Soeurs de la Charité de Nevers, 1978 a: 69). Respecto a la pobreza, desde su vocación como enfermera se dirigía siempre a los más pobres. “... la vocation de soeur de charité est précieuse parce qu'elle donne l'occasion de soulager les pauvres" (Archives Soeurs de la Charité de Nevers, 1978b: 84). 
diante la lengua del corazón ${ }^{9}$. Estas dos cualidades de la niña hacen referencia a los limpios de corazón y a los pobres y sencillos de las Bienaventuranzas.

Los Santuarios mediante sus diferentes Símbolos expresan la pobreza y la sencillez humanas, traducen la voluntad de perdón, conversión y elevan los corazones.

\subsection{VIVIR LOS SIGNOS.}

\section{EL GENTÍO: TURISTAS, VISITANTES, VOLUNTARIOS Y PEREGRINOS.}

Lourdes es el lugar donde la Virgen viene para ayudar a todos los que sufren, a los que ruegan y tiemblan, y el lugar donde la Virgen eligió a alguien cuyas miserias eran ridiculizadas por la sociedad egoísta en la que vivió Bernardita y por la sociedad en la que actualmente vive el ser humano. Lourdes reúne a todos aquellos que sufren y son, o se sienten, marginados y víctimas, y también a aquellos que llegan en acción de gracias.

Diferentes situaciones de sufrimiento, felicidad o de indiferencia pueden apreciarse en hombres y mujeres, niños, adolescentes y jóvenes, sanos y enfermos, que llegan a Lourdes para hablar a la Virgen con la esperanza y la certeza de ser escuchados y tratados de igual a igual. En Lourdes, como lugar de peregrinación y conversión, se produce una gran comunicación entre el Cielo y la Tierra, entre el Corazón del hombre y su Alma, entre la Virgen y la Conciencia, entre Bernardita y las Miserias de todos los que acuden a la orilla del río GAVE. Este lugar santo no deja indiferente a nadie porque nadie pasa desapercibido para la Virgen. Peregrinos, turistas, voluntarios y visitantes tienen su lugar en estos Santuarios. Todos, incluso los incrédulos pueden ver que Bernardita es el espejo en el que se reflejan los problemas del hombre actual.

Sin saberlo, las miserias que padecían Bernardita y su familia hace doscientos años se repiten hoy, y en Lourdes pueden ser comunicadas, confesadas. Pensemos en la miseria de los parados como el papá de Bernadette, las miserias de los sin techo que como la familia Soubirous no logran llevar una vida dentro de la normalidad, las miserias de aquellos que equivocadamente son considerados culpables de actos que no cometen como el papá de Bernadette al que tacharon de ladrón sólo porque era pobre. La miseria justificaba el robo y la consiguiente injusticia, las miserias de los analfabetos y de aquellos que no saben escribir sin faltas, de los que no tienen suficiente memoria para retener, o simplemente de aquellos a quienes se les considera torpes o tontos porque nadie se ha molestado en enseñarles, escucharles y orientarles, las miserias de los que tuvieron que dejar la escuela, la universidad para sacar adelante a hijos o familiares. Y las miserias de todos aquellos que no pueden hacer realidad sus sueños. En LOS SANTUARIOS todas estas miserias tienen cabida y son escuchadas.

Son muchos quienes sabiendo esto o sin saberlo, creyendo o sin creer acuden a Lourdes. La ciudad, como LOS SANTUARIOS, tienen diferentes lugares para acoger a esta gran diversidad de gente; alojamientos para un día; un fin de semana;

9 En la tercera aparición, Bernardita llevó papel y pluma para que la Virgen escribiera lo que deseaba, pero no era necesario, la Señora le pidió que fuera durante 15 días al mismo lugar y la niña lo entendió. 
unas horas o semanas; se venga solo; en familia o en grupo; en calidad de turista o peregrino; como visitante o curioso. Existen cientos de Hoteles, Residencias de Religiosas, Hogares y Albergues para hospedar a turistas, peregrinos y visitantes ${ }^{10}$. Los grupos de niños, adolescentes y jóvenes pueden alojarse en La Ciudad de los Jóvenes - "Le Village des Jeunes" que se encuentra en lo alto de la montaña. Y las personas que no pueden pagar un hotel y sufren algún tipo de exclusión o de injusticia pueden alojarse en La Ciudad San Pedro Cáritas - "La Cité Saint Pierre Secours Catholique" situada también en lo alto de la montaña. En La Pensión Familiar - "La Pension Familiale" pueden alojarse grupos o familias que desean compartir las tareas domésticas. Los voluntarios que acuden con la Hospitalidad de su país pueden alojarse en el Ave María, Hospitalet y St. Pierre y St. Paul ${ }^{11}$ entre otros.

\section{LOS ENFERMOS}

Lourdes es una ciudad hecha a la medida de los enfermos, éstos son atendidos en hospitales especialmente acondicionados para ellos. Ayudados por sus Responsables y Hospitalarios se dirigen a LA GRUTA por unas calles pensadas también para ellos, los enfermos en sus sillas o camillas tiradas por los voluntarios se deslizan por un carril que lleva hasta el interior de LOS SANTUARIOS. A ciertas horas del día, puede contemplarse la peregrinación de enfermos que, conducidos por responsables y voluntarios, acuden a $L A$ GRUTA, al rezo del Rosario, a la Procesión de las Antorchas, a las Piscinas...

Hay otros enfermos que sufren enfermedades escondidas, calladas. Hay quienes intentan dejar la droga y son acogidos en el CENÁCULO, centro creado por la Hermana italiana Sor Elvira para rehabilitar y reorientar a jóvenes y adultos mediante la fe y el rezo del rosario, fundamentalmente. Se encuentra a unos dos kilómetros de Lourdes. Existen otros centros especializados para minusválidos.

Todas estas personas llegan a Lourdes para cumplir los deseos de la Virgen y acuden a ella para hablarle de sus miserias, de esta miserable enfermedad que les impide llevar la vida que a ellos les gustaría. Bernardita vivió la miserable enfermedad durante toda su vida ${ }^{12}$ y ofreció su sufrimiento a Dios, podría decirse que nunca buscó dejar de sufrir, pedía fuerzas para soportar el dolor, ofrecía sus Miserias para la salvación y conversión de los hombres, y por las Almas del purgatorio. Esta actitud, que sólo puede ser de santos, explica que cualquier dolor aceptado y ofrecido es apreciado en el Cielo. Cuando una humillación hacía sufrir a la Santa lo llamaba

10 Pueden dirigirse a la Oficina de Turismo de Lourdes y consultar listados: http://www.lourdes-infoturisme.com

11 Ave María en el Centro de Lourdes, Hospitalet en el interior de Los Santuarios, Saint- Pierre y SaintPaul fuera y no muy lejos de los Santuarios. Más información en la página web de Los Santuarios: www. lourdes-france.org

12 Siendo religiosa en Nevers, le dijo a Sor Vincent que aceptaba la enfermedad como una caricia: "d'accepter la maladie comme une caresse". BERNADETTE DISAIT... (Archives Soeurs de la Charité de Nevers, 1978c:84). 
caramelo, en francés: "un bonbon" ${ }^{13}$. Cuando hablamos de Lourdes y de su mensaje, ¿hablamos quizá de las miserias transformadas en bombones y perfumes? ¿Será posible que voluntarios, peregrinos, visitantes y turistas puedan saborear y oler esta posibilidad? ¿Qué puedan sentir esta transformación en ellos mismos y en los demás? ${ }^{14}$

Pensemos que el Papa Juan Pablo II en el año 2004 acudió a LA GRUTA y en actitud de recogimiento bebió del agua, rezó el rosario y participó en las diferentes procesiones. Como peregrino y enfermo saboreó el perfume de la enfermedad. Alojado en el CENTRO DE ACOGIDA NUESTRA SEÑORA podía contemplar sin duda el clima especial que vive el enfermo en torno a la Gruta.

\section{LA ROCA}

La Virgen se apareció en una cueva por el interior de la cual se va pasando y tocando la roca en la que se asienta la fe del creyente y que pretende ser firme y dice: Señor en ti confío.

\section{EL AGUA}

El agua como elemento purificador es muy importante, tanto a nivel físico como espiritual, porque representa la esperanza de ser curado física, moral y espiritualmente. La esperanza de ser ayudado por Aquella que sabe lo pasa tanto en el interior como en el exterior del hombre. Cualquier peregrino o visitante que llega al Santuario y desea recibir su baño puede acudir respetando un horario determinado a LAS PISCINAS y ser sumergido durante unos segundos en este agua bendita. La Virgen espera con los brazos abiertos a cada persona que ha decidido venir a cumplir su voluntad: "Vengan a beber y a lavarse."

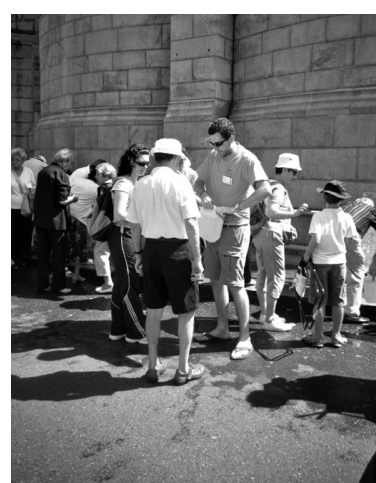

Foto 3. Voluntarios en Las Fuentes.

13 Una Sor de la Caridad de Nevers cuenta que Bernardita cada vez que se sentía humillada por alguna llamada de atención lo consideraba un caramelo. 80. "Quand elle était réprimandée ou recevait quelque humiliation, elle me disait: - Je viens de recevoir un bonbon."

(Archives Soeurs de la Charité de Nevers, 1978d: 66)

14 La contemplación en la Capilla de la Adoración en LOS SANTUARIOS de un grupo de jóvenes rezando, cantando y llorando a La Miserable dependencia de la droga, puede iluminar toda una vida, transformarla. 


\section{LA LUZ}

El gesto de coger una vela y encenderla es el gesto que realizaba Bernardita cuando acudía a las citas con la Virgen ${ }^{15}$. La persona que acude a la Gruta repite el gesto de la niña. Se puede dar testimonio de que se ha bebido del agua, estado en la Gruta, tocado la roca y participado en una procesión o en una celebración depositando una vela encendida junto a las demás velas.

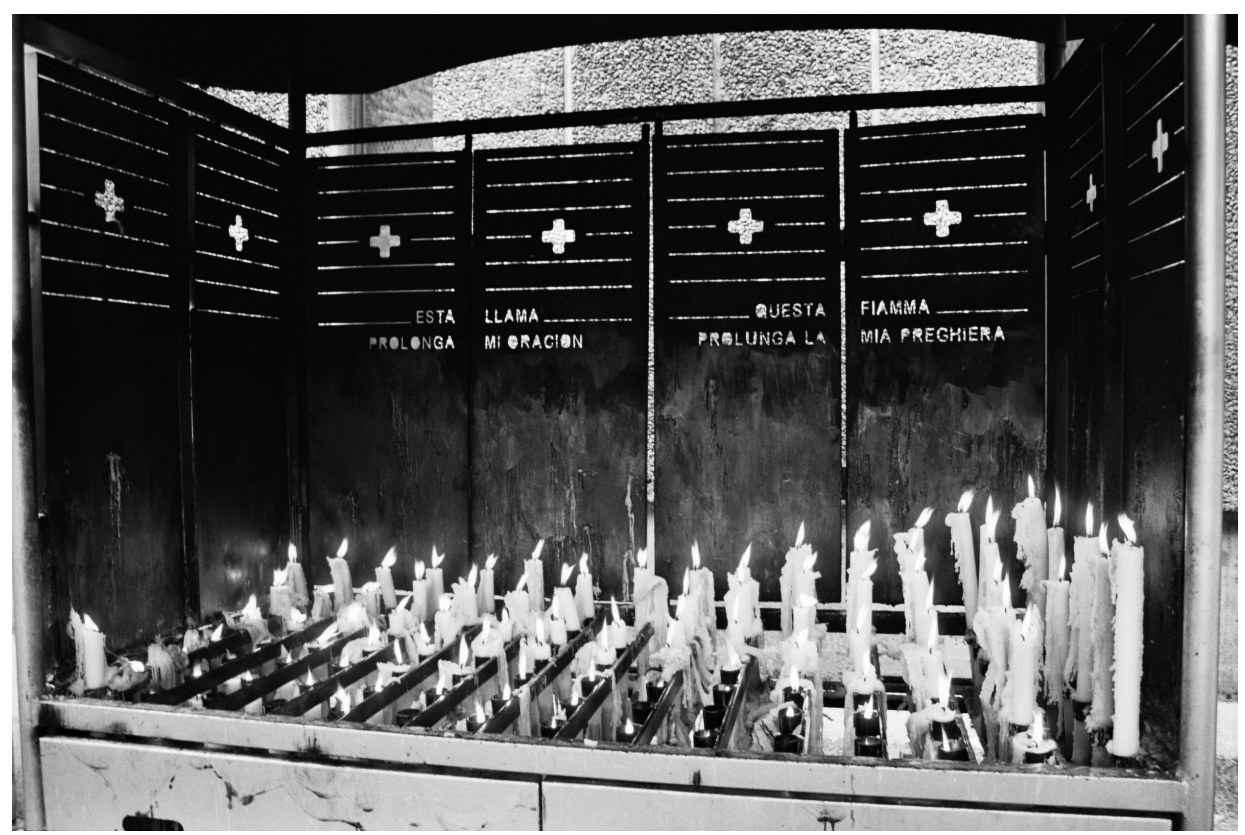

Foto 4. La vela encendida representa cada presencia, cada persona particular que junto a otras personas cree y espera, reza y confía.

1.5 CONCLUSIONES. FRUTOS DE LOURDES. EL MENSAJE DE LOURDES Y EL TEMA PASTORAL ANUAL.

- Todos los hombres son iguales ante Dios. Bernardita decía que la Virgen le hablaba y se dirigía a ella como una persona a otra persona, sin diferencias de ningún tipo y con mucha bondad. La Virgen se hizo pequeña como Bernardita para hablarle de igual a igual.

- En situaciones de sufrimiento, todos, jóvenes y mayores, sanos y enfermos, hombres y mujeres pueden rezar y participar en las Procesiones según el deseo de la Señora. Todos los que con su presencia forman parte del clima silencioso, callado y devoto de LOS SANTUARIOS son testigos de esperanza y caridad.

15 En la Cuarta aparición no hubo mensaje sino gesto, ese día, Bernardita lleva a LA GRUTA un cirio bendecido que siempre llevará después hasta la Aparición 14. 
- $\quad$ En uno de los mensajes, la Virgen desea que se venga en procesión. Este deseo lo expresa cada hombre cuando llega a LOS SANTUARIOS y se dirige a la Gruta. Al cumplir el deseo de la Madre, los hijos logran cumplir los propios, esos deseos apenas audibles del alma.

- Lourdes como centro mundial de peregrinación es un centro del alma y para el alma. Esta vida del alma dejada en manos de la Señora puede alcanzar su sueño.

Todos los años en Los Santuarios hay un tema pastoral ${ }^{16}$ y alrededor de éste se organizan las diferentes actividades con el fin de acercar el mensaje de Lourdes a quienes participan en ellas, ayudándoles a vivir su propia peregrinación. Si la Virgen y Bernardita esperan con los brazos abiertos al peregrino, voluntario y visitante o turista, también su despedida es abierta, generosa y triunfal.

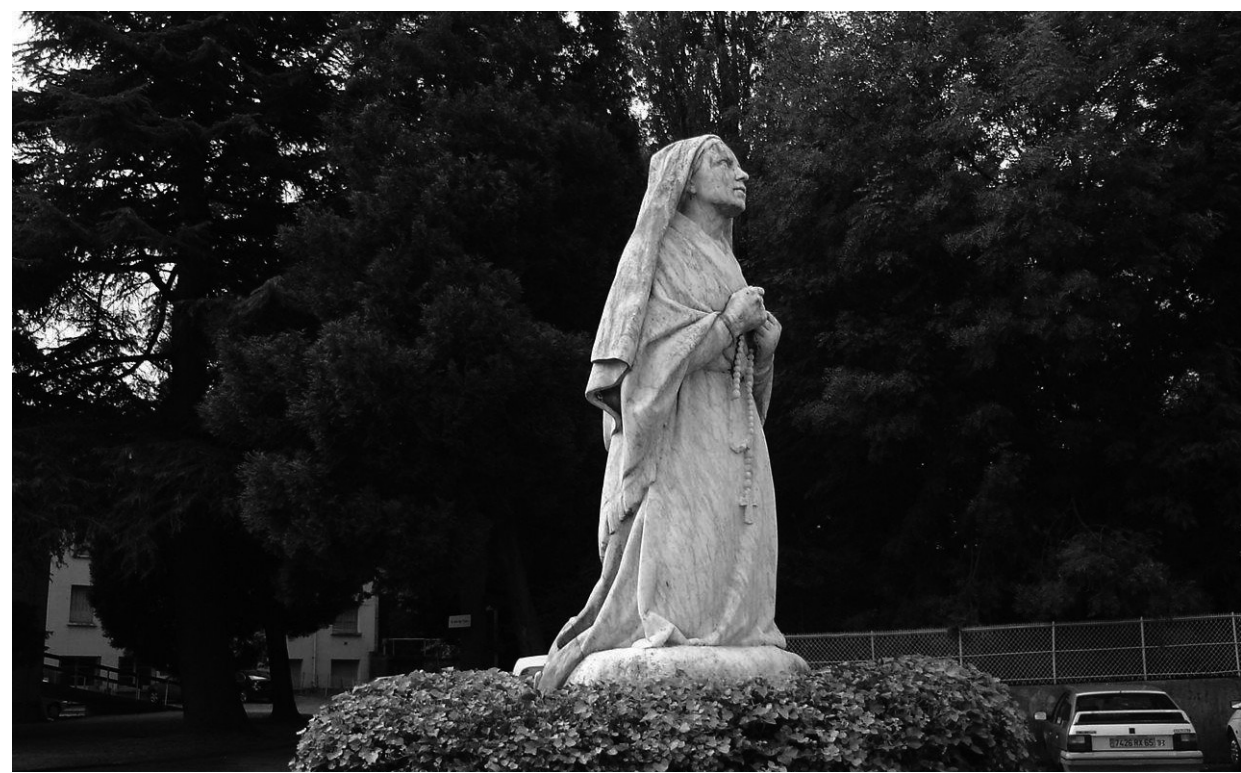

Foto 5. Estatua de Bernardita a la salida de La Basílica de S. Pío X en el interior de LOS SANTUARIOS. 


\section{6 ¿QUÉ ES BARTRÈS?}

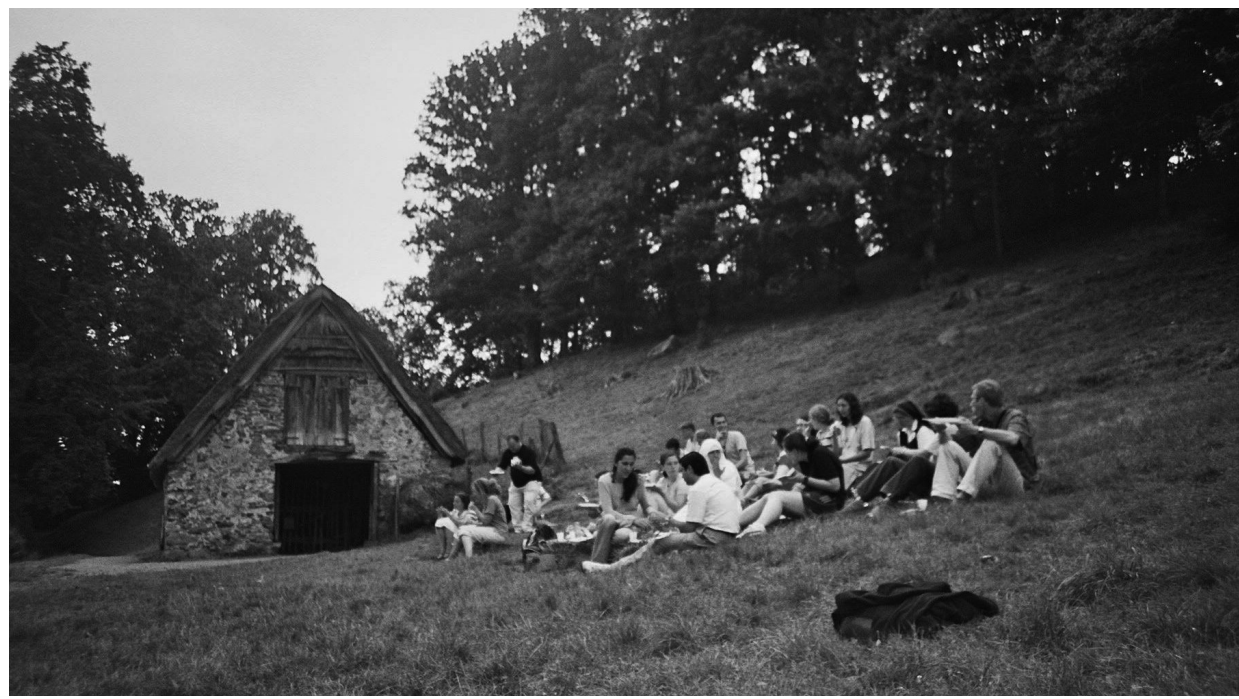

Foto 6. Grupo de voluntarios: Picnic en la pradera del aprisco de Bartrès donde Bernardita cuidaba de las ovejas.

Es un pueblo situado a unos 4 kilómetros de Lourdes al que Bernardita fue dos veces. La primera vez era un bebé17 y la segunda vez Bernardita tenía 14 años y fue para ocuparse de las ovejas de esta misma señora. Para el peregrino, turista o visitante ir a BARTRÈS es otra peregrinación, el recorrido que realizaba la niña todas las semanas desde Lourdes puede repetirse hoy incluso en coche. Puede visitarse la casa y granja de la nodriza, la iglesia parroquial y el aprisco donde cuidaba de las ovejas. En este lugar la niña no fue muy feliz, nada feliz, su sueño irrealizable al no poder hacer la Comunión le hace volver a Lourdes para nunca más volver a BARTRĖS después de 4 meses de sufrimiento. Su sueño lo realizaría en Lourdes cuando se abandonó por completo al dolor y cuando se puso por completo en manos de Dios, entonces la Virgen con sus Apariciones le ayudó a realizar su sueño: recibir la Comunión.

"En ocasiones, es a través de un largo camino a través de la vida que uno consigue cumplir su sueño".

Esta cita del escritor Jacques Chardonne ${ }^{18}$ es aplicable a todos aquellos que se sienten defraudados y desconsolados como Bernardita y deciden dejar su vida en manos de Dios. Pero este camino de abandonarse en Dios es quizá lo difícil. ¿Cómo abrir el corazón a los deseos de Dios? ¿Cómo oír sus palabras? ¿Cómo dejarse acunar en sus brazos cuándo se está mal? Entonces Lourdes es un abandonarse a la voluntad

17 Bernardita tenía diez meses y su madre no podía darle el pecho. Marie Laguës, una vecina de Bartrès que había perdido a su hijo de 13 días, amamantó a Bernardita. Esta situación duraría diecisiete meses, desde noviembre de 1844 hasta abril de 1846.

18 Escritor francés (1884-1968) recibe de la Academia Francesa el premio por su novela CLAIRE en 1932. 
de Dios y al deseo de la Virgen, como lo hizo Bernardita, también es sabido que después de Lourdes, la niña, pudo cumplir su otro sueño; ser enfermera, pero también se sabe que a lo largo de su vida nunca dejó de recibir bombones de sufrimiento, quizá el mensaje de Lourdes sea el camino recorrido por Bernardita, un camino en el que el hombre puede hacer realidad sus diferentes sueños pero con pequeños trechos de dolor debidos a las miserias humanas: violencia, injusticia, pobreza, enfermedad, dependencia... sentimientos de abandono y fracaso. En cualquier caso, para Bernardita, BARTRÈS no fue sinónimo de felicidad sino de dolor.

La persona que recorre andando el camino que lleva a Bartrès o se desplaza en coche y visita los lugares en los que estuvo la adolescente, recorre en cierto modo el peregrinaje de la niña y el suyo propio.

Lourdes - Bartrès - Bartrès - Lourdes: como Bernardita, la persona que acude a Lourdes viene a vivir su propia peregrinación, su evolución física, mental y espiritual. Ya se venga como enfermo, como desilusionado y decepcionado del mundo y de los hombres, como víctima o verdugo, como dependiente o independiente, como voluntario desde una inquietud religiosa o solidaria, como turista incrédulo o visitante escéptico, o como fiel creyente que viene a vivir de forma intensa su fe, Lourdes está ahí con sus Santuarios para responder a cada uno en su justa medida. Como centro mariano de peregrinación todo el mundo es acogido y guiado a través de sus signos. El grado de participación e implicación se hace desde la libertad y varía según las necesidades, motivaciones y objetivos de cada persona.

El turista que veranea en los Valles del Pirineo o el visitante que "pasaba por ahí" aprovecha para venir a Lourdes y ver qué es. Contempla sus Santuarios y sus signos como contempla durante unos minutos, horas o segundos un cuadro o un lago, y ésta será su experiencia callada pero intensa de su paso por el lado sagrado de su actividad turística y cultural. Su mini peregrinación forma parte de un turismo religioso y natural; el arte sacro y la naturaleza al servicio de la cultura acercan el hombre a su parte espiritual, y en cierta medida, a sus raíces.

Aquella persona que decide participar activamente en la vida de los Santuarios y estar al servicio de los demás será voluntario, vivirá profundamente los signos y el tema pastoral de Lourdes, y lo transmitirá con su sonrisa, su mirada, su corazón y sus brazos a los demás. Finalmente, quien llega solo, en familia o en grupo para vivir profundamente una peregrinación la vivirá hacia adentro y en el silencio y la paz que transmiten Los Santuarios durante un mínimo de dos o tres días ${ }^{19}$.

En la identificación con Bernardita, el peregrino reconoce el dolor y el sufrimiento como parte de su evolución física, mental y espiritual. Pero también puede respirar y tocar la riqueza natural del Valle Pirenaico, sentir la gran riqueza espiritual de los signos de Lourdes y contemplar la esplendida riqueza artística de sus edificaciones.

19 En sentido estricto, venir en peregrinación exige un mínimo de tres días. En sentido figurado, la peregrinación hace referencia a la persona que llega a Lourdes y vive su experiencia sin importar el tiempo de su estancia. En este trabajo, hacemos referencia a la segunda acepción. En Lourdes, por ejemplo, los peregrinos de un día son muy comunes. 


\subsection{LAS EDIFICACIONES DE LOS SANTUARIOS.}

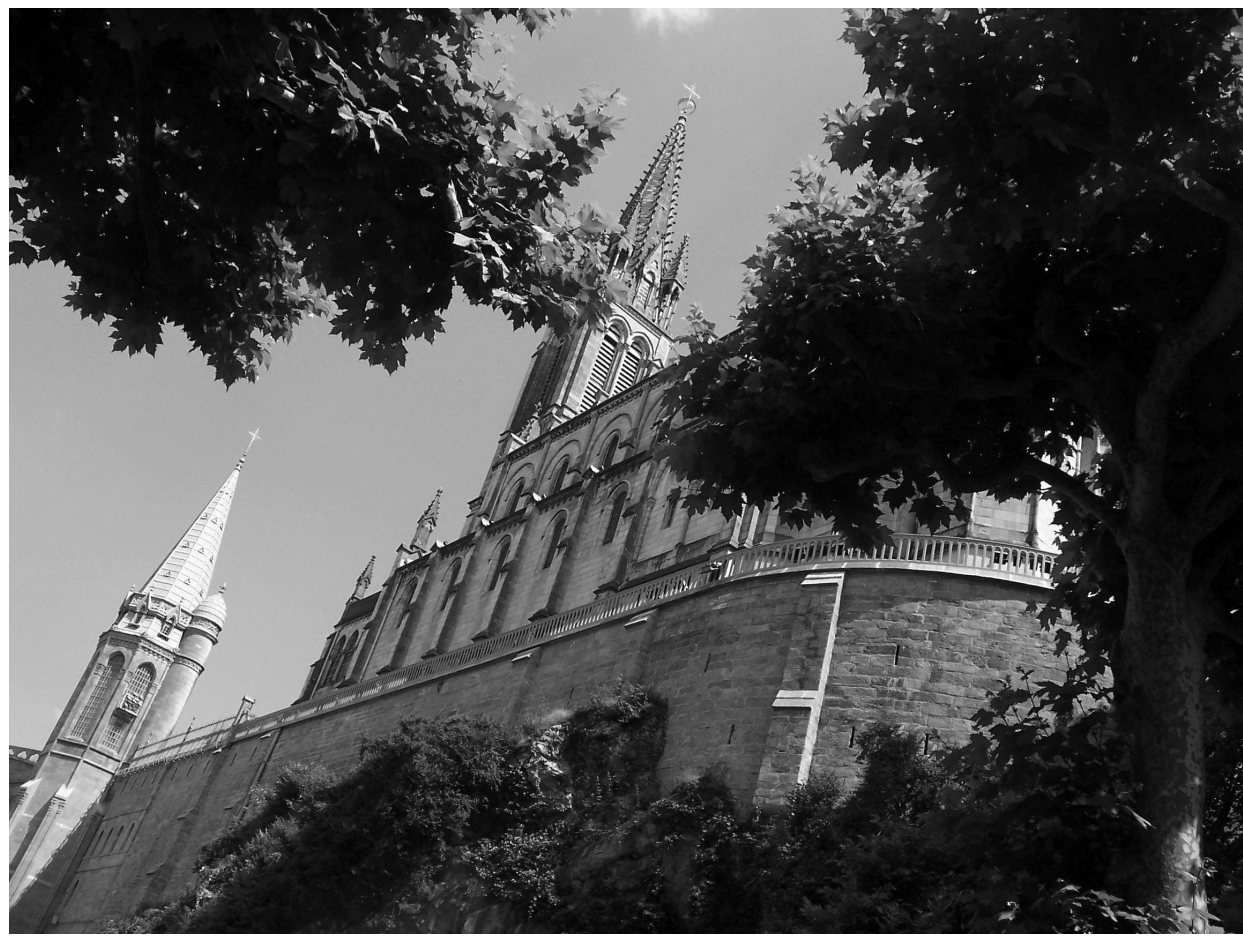

Foto 7.Vista de las primeras edificaciones sobre la Gruta.

La riqueza artística de sus diferentes construcciones ayuda a ver que el arte forma parte del clima de reflexión y oración que se vive en este lugar. Tanto el turista, el visitante como el peregrino y el voluntario pueden empaparse de la historia de cada edificación. Como voluntario se puede ser Guía religioso de los Santuarios y explicar tanto el interior como el exterior de cada Iglesia, Basílica o Cripta.

En 1862 el Obispo Laurence toma en serio las Apariciones y decide empezar la construcción encima de La Gruta de diferentes Capillas. Cada edificación es la expresión concreta de un matiz del mensaje de Lourdes. A este conjunto de edificaciones en torno a La Gruta se le denomina LOS SANTUARIOS: Puertas, Puentes, Rotondas, Pabellones, Basílicas, Iglesias, Cripta y Capillas. Sin olvidar Las Piscinas, la Gruta, Las Fuentes, La Pradera, La Tienda de la Adoración, El Camino del Agua, La Explanada. Todas estas edificaciones pueden verse desde la página Web de Los 
Santuarios $^{20}$. Las tres edificaciones que se encuentran sobre la Gruta son las primeras construcciones y, en su caso, podemos hablar de Basílicas ${ }^{21}$.

La Cripta es la primera construcción que se hizo sobre la roca de la Gruta de Massiabelle de 1863 a 1866. Bernardita estuvo en su inauguración pues su padre ese año de 1866 estaba enfermo y ella retrasó su viaje a Nevers para estar más tiempo con él. Después se marchó y nunca más volvería a Lourdes ${ }^{22}$.

La Basílica de la Inmaculada Concepción se comunica con la Basílica del Rosario, su construcción comienza en 1862 encima de la Cripta con piedra de Lourdes, es llamada también Basílica Superior ${ }^{23}$. En 1863 se empieza la construcción de La

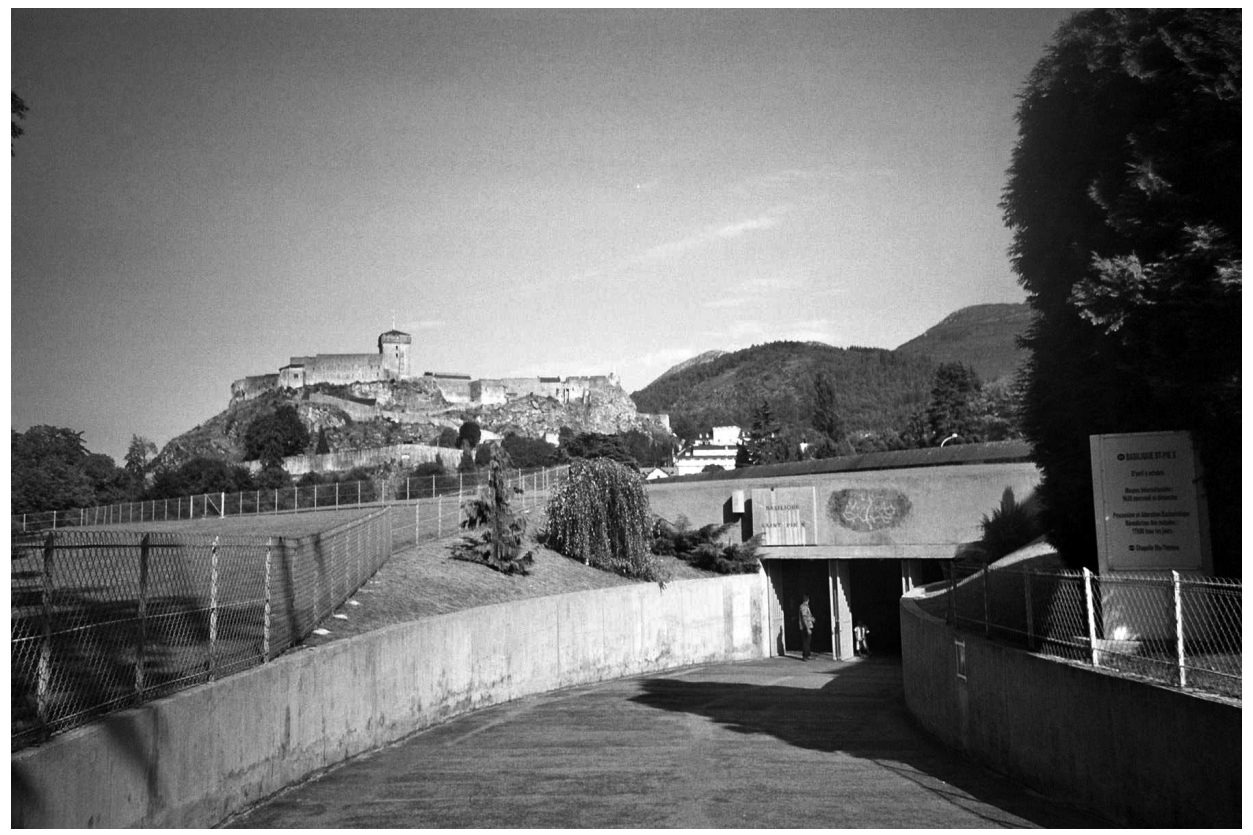

Foto 8. Una de las entradas a La Basílica Subterránea San Pío X y al fondo el Castillo por el que pasaron Carlomagno, el Príncipe Negro y Duguesclin.

20 Página web de los Santuarios: http://www.lourdes-france.com/es/

y en http:/www.lourdes-france.org puede seguirse en directo la vida de los Santuarios, la Gruta en directo las 24h, y descubrir el mensaje de Lourdes, sus signos, su tema pastoral...

21 Son varios los Papas presentes en cada una de ellas; Pío X y Pío IX, León XIII y Pío XII. Al entrar a La Cripta y a la derecha, San Pedro, bello y majestuoso, nos recibe y frente a él, el Papa Pío X dando la comunión a un niño como signo del deseo tan grande de Bernardita por hacer su comunión.

22Que nunca volviera no significa que no recordara su querida tierra, muchas son las veces que con nostalgia y cariño piensa en la Gruta.

23 Por ser la edificación más elevada. Se consagra por el Arzobispo de Paris, el Cardenal Guibert. Puede acoger en torno a 800 personas. Cabe resaltar que la estatua de la Virgen que se encuentra en el pilar a la derecha del altar realizada por el artista parisino Cabuchet es, según Bernardita, la que más se parece a la Virgen. 
Basílica del Rosario porque las edificaciones anteriores no pueden acoger a todos los peregrinos que llegan a Lourdes ${ }^{24}$. Pero cada vez llegan más personas, pensando en la afluencia de enfermos y en el tiempo lluvioso se construye La Basílica Subterránea San Pío $X$, una construcción subterránea gigantesca ${ }^{25}$.

Al otro lado del Gave y frente a la Gruta se encuentra La Iglesia de Santa Bernardita y La Capilla de la Adoración ${ }^{26}$.

Las Piscinas se encuentran al lado de la Gruta, primero la de los hombres y a continuación, la de las mujeres ${ }^{27}$.

La Gruta Massiabelle cuyo nombre significa roca vieja ${ }^{28}$ es el lugar privilegiado de LOS SANTUARIOS. Por la Puerta de San José se llega a La Explanada donde se encuentra la estatua de La virgen Coronada. Su Corona es signo del triunfo de la Virgen sobre el mal.

La idea según la cual, el Bien es más fuerte que el Mal gracias al Amor fue expresada por el Papa Benedicto XVI en su viaje a Lourdes, los días 13, 14 y 15 de septiembre de 2008, cuando expresa que el poder del amor es más fuerte que cualquier fuerza de mal sobre los hombres.

La forma adoptada por los arcos, a la entrada de LOS SANTUARIOS, hacen pensar en los brazos de la Virgen acogiendo a los peregrinos, dos rampas de 130 metros de larga cada una que abrazan a las 80000 personas que puede contener $L a$ Explanada.

LOS SANTUARIOS cuentan con otros $\operatorname{lugares}^{29}$ que ayudan a vivir cada mensa-

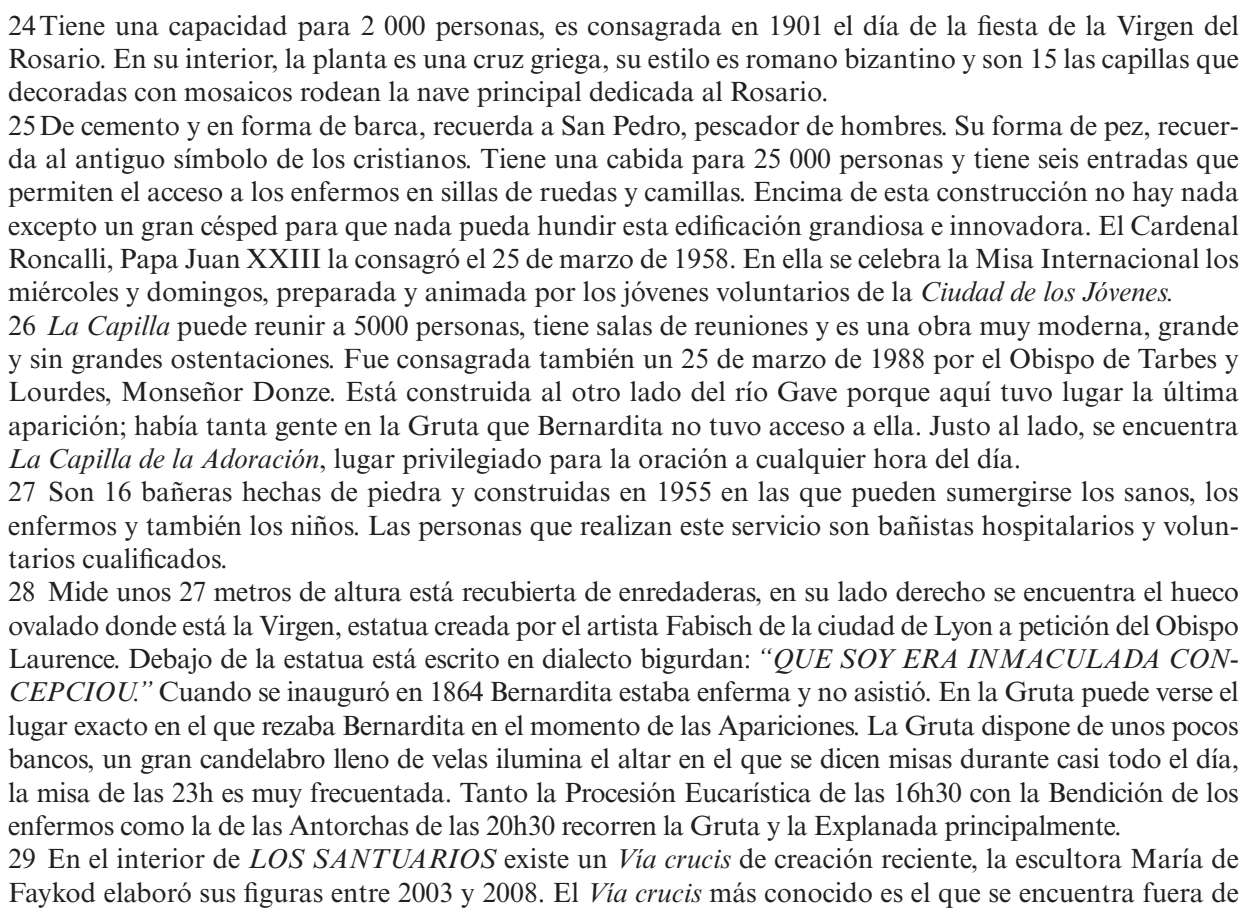


je y signo ${ }^{30}$. Para obtener información sobre todas estas edificaciones, y reservar misas en las diferentes Capillas, Basílicas y en La Gruta hay que dirigirse al Centro de Información: FORUM CENTRE D'INFORMATION. Aquí pueden conseguirse planos, horarios, folletos, y explicaciones detalladas sobre la vida en LOS SANTUARIOS. Pueden verse videos y asistir a conferencias sobre apariciones, curaciones y milagros.

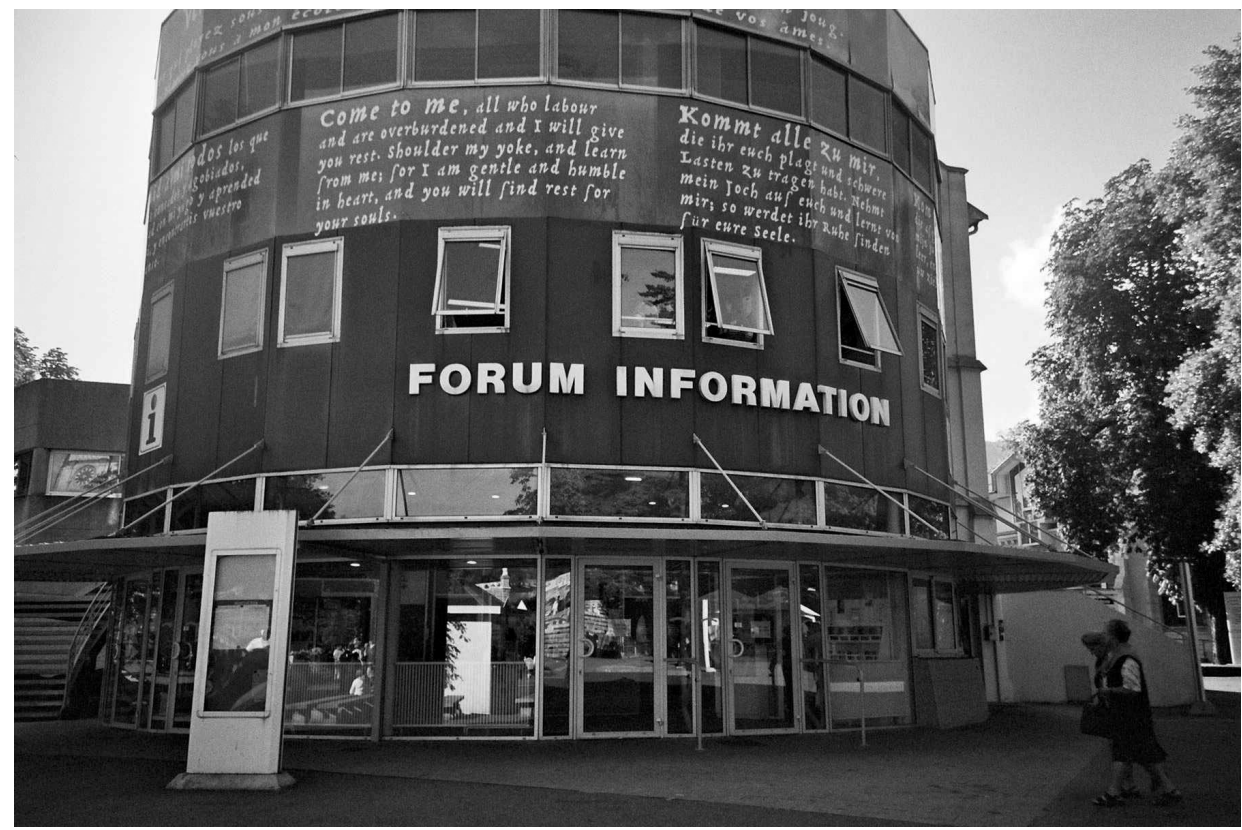

Foto 9. Centro de Información Forum en el interior de Los Santuarios.

\subsection{LOURDES COMO CENTRO DE VOLUNTARIADO}

Hablamos de un voluntariado realizado durante el verano cuando la afluencia de peregrinos desborda a Los Santuarios, pero se puede ser voluntario durante todo el año. Son diferentes las posibilidades de hacer voluntariado en Lourdes; jóvenes, adultos, jubilados pueden ser voluntarios. Las tareas a desarrollar son diferentes y dependen del perfil de cada persona y de lo que quiera o busque cada una. Se aconseja un tiempo de quince días para vivir esta experiencia, entre quince y veinte días dependiendo también del criterio seguido por cada organismo en el que se solicita el servicio.

Hay que recordar que la Virgen pide a Bernardita que venga a La Gruta durante quince días y que la niña cumplió esta petición con seriedad y entusiasmo, con actitud

LOS SANTUARIOS en la cuesta de Espelugues. Fue inaugurado en 1912 y tiene unas estatuas de dos metros creadas por el escultor Raffl a lo largo de quince estaciones

30 Existen otros lugares en los que no nos detenemos como el recorrido litúrgico del agua a lo largo del río Gave, el pabellón de las confesiones o el centro médico para las curaciones, entre otros. 
desinteresada y sin saber cómo iban a desarrollarse los acontecimientos, creía en lo que hacía, se fiaba de lo que la Virgen le transmitía y cumplió lo solicitado. Ésta es la actitud de la persona que se decide y anima a venir como voluntaria a Lourdes, ella, Bernardita es el modelo a seguir y desde la confianza se desempeña una labor que puede gustar más o menos, pero es la tarea encomendada y debe cumplirse con alegría y humildad.

Cuando la persona interesada no disponga de este tiempo de quince días puede proponer el tiempo del que disponga y hablarlo con el centro. Es recomendable tener un nivel intermedio de Lengua Francesa aunque depende también de los requisitos solicitados por cada organismo, y de los objetivos marcados por cada voluntario. Estos conocimientos refuerzan y maximizan las relaciones con los demás y optimizan las tareas a llevar a cabo.

Los Centros que acogen voluntarios durante todo el año son los siguientes:

- $\quad$ El Servicio Piloto "Service Pilotes» Los voluntarios, en su mayoría jóvenes y adultos, acogen a los peregrinos, visitantes y turistas que llegan a Los Santuarios y les informan sobre los lugares de culto, los horarios y las diferentes actividades. Se aconseja el conocimiento de idiomas y unas buenas condiciones físicas. Se trata de un voluntariado realizado en el interior de Los Santuarios. Web: http://fr.lourdes-france.org/sejour-a-lourdes/benevoles/pilotes

- La Ciudad de los Jóvenes «Le Service des Jeunes» Los voluntarios son sólo jóvenes que forman parte de un Grupo Internacional de Jóvenes al servicio de otros jóvenes y de Scouts que llegan a Lourdes y a la Ciudad de los Jóvenes de todos los rincones del mundo. Se recomienda un nivel intermedio de francés. Los voluntarios se alojan en La Ciudad de los Jóvenes emplazada en lo alto de la montaña pirenaica y desempeñan su servicio tanto aquí como en Los Santuarios y en Lourdes.

Web: http://fr.lourdes-france.org/jeunes/servir/service/-jeunes

- La Hospitalidad Nuestra Señora de Lourdes «Hospitalité Notre Dame de Lourdes». Nouvel Accueil Jean Paul II. Jóvenes y adultos al servicio de la Hospitalidad y atendiendo a los enfermos. No es necesario saber francés en las peregrinaciones de corta duración cuando enfermo y voluntario son de la misma nacionalidad ni cuando se es voluntario en el propio edificio de la Hospitalidad o en las Piscinas. Para ser hospitalario hay que dirigirse a la Hospitalidad de cada ciudad. En el caso de la de Lourdes, se solicita en la Web: http://fr.lourdesfrance.org/sejour-à-lourdes/bénévoles

- La Ciudad San Pedro "La Cité Saint Pierre, Secours Catholique-Avenue Mgr Rodhain- Jóvenes y adultos al servicio de los peregrinos alojados en la Cité y de los visitantes que vienen a conocerla. El servicio de voluntariado se realiza en la propia Cité emplazada en la montaña Pirenaica donde se respira el clima apacible y silencioso de sus palabras de bienvenida: Paz, Silencio, Paz. Aunque el francés no es imprescindible se recomiendan unos conocimientos básicos. Web: www.citesaintpierre.net

- La Asunción «Assomption-Maison de prières»-21, avenue Antoine Béguère. 
La actividad de voluntariado que aquí se presenta ha sido llevada a cabo por jóvenes universitarios en la Ciudad de los Jóvenes y en la Ciudad San Pedro al servicio de Los Santuarios, de los peregrinos y visitantes, nunca al servicio de los enfermos, salvo en el servicio llevado a cabo en Las Piscinas.

Las fotos que aparecen se realizaron durante la estancia en Lourdes de los voluntarios de la Universidad CEU San Pablo: Clara, Elena, Lucía, Sergio, Carmen, Cristina, Nuria, Marcelo, Inma, Elva, Béatrice, Borja y Gabriela.

Se puede acudir a Lourdes como voluntario con el propósito de aprender y mejorar el nivel de lengua francesa o con la ilusión de vivir una experiencia nueva de convivencia y trabajo en equipo. Esta inquietud solidaria o religiosa puede verse desbordada por el trabajo en un grupo multicultural: franceses, italianos, ingleses. En Lourdes se puede practicar no sólo el francés sino el coreano, el inglés, pasando por el italiano, el polaco... Los primeros dos o tres días suelen ser de formación, una explicación pormenorizada de lo que va a ser la tarea a desarrollar, deja presagiar que la actividad va a ser frenética durante toda la estancia: guiar a grupos, alojar a los peregrinos en las instalaciones, limpiar los pabellones, organizar encuentros internacionales... la labor puede ser intensa, pero no una carga. Normalmente el voluntario se siente capacitado para realizar el servicio asignado y además hay que contar con el compañerismo y la disposición de todo el equipo, es fácil entonces que la dificultad se convierta en pura entrega y acto altruista, que no se tenga en cuenta ni el cansancio, ni la dificultad para expresarse en otra lengua... todo fluye y en pocos días todas las dificultades desaparecen. Cuando se piensa en la vida de Bernardita y en su sufrimiento no se puede ser egoísta ni tener miedo al fracaso.

El voluntario que humildemente se pone al servicio de los demás, de los peregrinos y de los enfermos llegados del mundo entero se prepara para vivir una experiencia agotadora e inevitablemente inolvidable. El voluntario piensa en Bernardita y la imita, ella es su modelo. El voluntario es testigo de la evolución de la(s) persona(s) a la(s) que sirve, y a su vez, él también vive, aunque a veces no lo sepa, su propia peregrinación, su propio viaje espiritual a través de su entrega a los demás y de su estancia en este lugar mariano. Se da a los demás, se olvida de sí mismo, a veces ocurre que quiere tener un tiempo para él y no logra tener unos minutos de descanso. Entre los que son servidos y los que sirven se establece una humilde pero sabia complicidad; la de saber que una Miseria de hoy se puede transformar en un Sueño de mañana, y que un peregrino, turista o visitante de hoy se puede transformar en un voluntario de mañana. Esta lección enriquecedora favorece la dinámica de grupo y el trabajo en equipo.

Vivir una experiencia de voluntariado proporciona una formación integral a la persona que mediante su acción solidaria se pone al servicio de los demás. Es una experiencia enriquecedora porque participa en la vida social de otra nación, que a su vez, se relaciona con otras naciones, y porque forma parte de un equipo de personas de distintas nacionalidades con el deseo de acoger y ayudar al peregrino, visitante o turista.

El voluntario firma un compromiso mediante el cual se compromete con él mismo y con los demás a ponerse durante un tiempo al servicio de los demás des- 
interesadamente. Durante este periodo aprende a maximizar sus recursos humanos, sociales e incluso lingüísticos.

Si se trata del voluntariado en $L A C I U D A D S A N$ PEDRO, el voluntario joven o adulto puede realizar tareas muy diversas. Puede ser recepcionista, guía, puede ocuparse de tareas domésticas en los comedores, tareas técnicas en el mantenimiento de los edificios, de limpieza, e incluso puede ocuparse de las zonas verdes. Puede formar parte de otros equipos dedicados a preparar misas y encuentros. Todo depende del perfil, de la disponibilidad del voluntario y de las necesidades de la Cité en ese momento.

El voluntario que hable francés puede acceder más fácilmente a las diferentes actividades que se proponen, puede permanecer en la Recepción de los diferentes edificios e incluso puede ser guía. Aunque hay que decir que son numerosos los voluntarios que aquí acuden sin saber francés y pueden vivir una experiencia de voluntariado enriquecedora. Recordemos que las personas alojadas en la Cité son peregrinos que vienen de cualquier parte del mundo al encuentro de una sonrisa, una mirada y un gesto de paz, y este mensaje puede ser transmitido con el sencillo lenguaje del corazón como fue el caso entre la Virgen y Bernardita.

El lema del fundador de la Ciudad de San Pedro Caritas Francia, Monseñor Rodhain es: "La Caridad no tiene hora" basándose en la cita bíblica: "Tuve hambre y me disteis de comer, tuve sed y me disteis de beber, era forastero y me acogisteis, estaba desnudo y me vestisteis, ..."(San Mateo, 25)

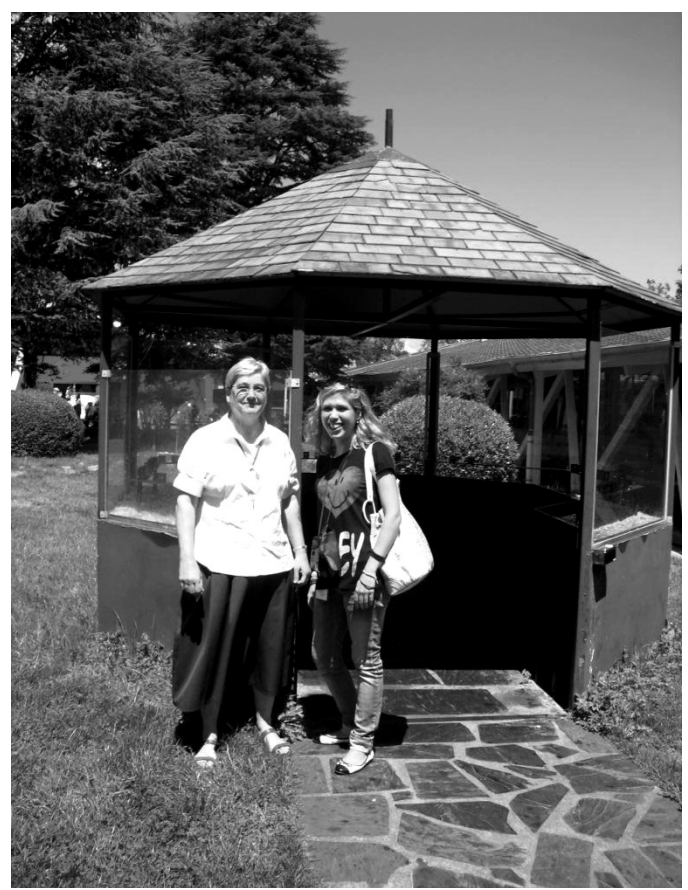

Foto 10. Voluntarias en La Cité San Pedro.
Una joven voluntaria de la Universidad San Pablo CEU expresa:

"Tras varios días en la Cité me di cuenta que todos teníamos algún motivo para estar allí, cada cual más diferente: el mío estaba claro, pretendía aprovechar la oportunidad que me brindaba la Universidad para estar al servicio de los demás durante esas dos semanas y al mismo tiempo mejorar mi comunicación en francés. Dicho así parece muy poco tiempo pero realmente esas dos semanas resultaron ser fructíferas, pues descubrí una realidad que desconocía y la fortaleza que puede emerger en nosotros mismos ante ciertos momentos de dificultad y de soledad, pues la Cité es un lugar que se presta para ello, la reflexión, en parte debido a esa paz que envuelve Lourdes." 
En LA CIUDAD DE LOS JÓVENES el voluntario en su tarea como guía, explica en francés o en la lengua que domina y por la ciudad de Lourdes y en Los Santuarios, la biografía que antes se ha estudiado de Santa Bernardita haciéndose responsable de un grupo de jóvenes o de scout. También puede explicar las distintas edificaciones del Santuario, sus características, estilos y decoración. Puede ocupar puestos en la Recepción de la Ciudad de los Jóvenes y puede participar en diferentes actividades como la preparación de la Misa internacional, preparación y organización de cantos y lecturas. También puede acudir a los hospitales para ayudar en el comedor, y a las piscinas para ayudar a las personas a tomar su baño.

La Lengua Francesa es la herramienta de comunicación a utilizar en el trato con los peregrinos y voluntarios. El Voluntariado Internacional en Lengua France$s a$ permite que el voluntario pueda mejorar su nivel, adquiriendo y ampliando el vocabulario de francés genérico y especializado. Aprende a maximizar sus recursos lingüísticos y rompe la barrera del miedo para comunicarse en lengua francesa. Logra integrarla de forma natural en su vida personal, académica y profesional. Por las características de esta experiencia, los participantes enriquecen su formación, educación y sensibilidad.

Esta estancia para el joven, si es universitario, es el paso previo para solicitar una $B E C A E R A S M U S$ en un país francófono. El sentimiento de sentirse útil y de saberse capaz de llevar a cabo lo que se le ha encomendado le ayuda a creer en sí mismo. El voluntario adquiere seguridad en sí mismo para desenvolverse en el mundo social, académico, profesional y laboral. Durante esta estancia todos los voluntarios entablan lazos de amistad que pueden consolidarse y perdurar en el tiempo. La dinámica de grupo potencia la solidaridad y la generosidad entre los voluntarios. No hay que olvidar que del trabajo en equipo surge una verdadera convivencia, un vínculo estrecho del que emana simpatía, diversión, entrega... Gracias a todo esto, se entablan grandes amistades que pueden consolidarse.

Esta formación integral del voluntario enlaza su formación académica y el consiguiente perfeccionamiento de la Lengua Francesa, con su formación humana y el consiguiente desarrollo de su capacidad solidaria así como la consolidación de su carácter.

En cualquier caso, se trate del joven o del adulto, en La Ciudad de los Jóvenes, en La Ciudad de San Pedro, o en otro organismo, el voluntario fortalece su formación humana frente a la comprensión de sí mismo y de los demás. El serio cumplimiento de cada tarea encomendada permite crear una dinámica de grupo en la que el voluntario puede sentir que su tarea está bien hecha y se siente

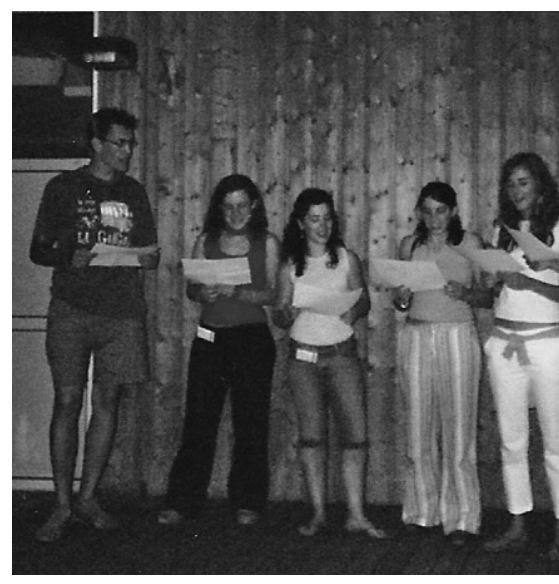

Foto 11. Voluntarios en la Ciudad de los Jóvenes. 
útil, capaz, feliz. La conciencia del trabajo bien hecho le permite creer en él mismo, los demás a su vez creen en él. Se siente responsable y aprende a estar disponible. Con su actitud de servicio a los demás aprende a maximizar sus recursos sociales y humanos. La entrega al prójimo va calando de una forma profunda. Hasta el más escéptico puede sentir la sensación de que algo especial se respira en el ambiente, y es que Lourdes como centro de peregrinación invita a la meditación y hace aflorar esa parte que nosotros mismos intentamos no despertar; la vida del alma. Y es que es fácil que se vaya con "el chip" de la solidaridad y se vuelva con "el chip" de la espiritualidad.

Todas las experiencias como recepcionista, guía, animador... pueden ser más o menos fatigosas, pero todas son enriquecedoras, especialmente la vivida en las Piscinas $^{31}$. La dureza inicial de algunas situaciones anuncia la superación posterior para el voluntario que confía y se esfuerza. Es la idea expresada en el Canto del regreso del Salmo 126(125): "Los que van sembrando con lágrimas cosechan entre gritos de júbilo" (Sal, 126,5).

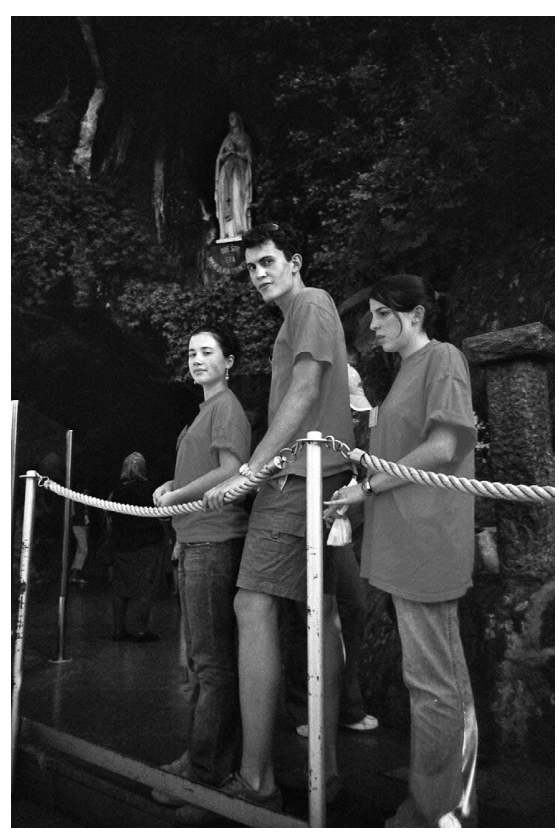

Foto 12. Jóvenes Voluntarios Universitarios en La Gruta.

Esta formación se ve fortalecida por el hecho mismo de estar en un centro de peregrinación. Cuando se está al servicio de los demás en este lugar mariano, y cuando se está en La Gruta tan cerca de la Señora, la Madonna, l'Aquéro ${ }^{32}$, se adquiere esa Fortaleza para enfrentarse a la vida, al sufrimiento y a la felicidad, desde la firme creencia en que nunca se está solo, como así lo creyó siempre Bernardita.

En conclusión, puede afirmarse que al final del viaje y después de una experiencia así, se siente el deseo que todo lo vivido allí no se quede detenido y estancado sino que, por el contrario, se desea que esta experiencia enriquecedora se repita en otras personas. Este deseo de prolongación del hombre en otros hombres es el reflejo de vivir lo particular en lo general y de ver que cada vida tiene un aspecto material y otro espiritual que se refleja en la Luz de todas las velas encendidas y depositadas en Los Santuarios. Después de Lourdes, los frutos de esta luz podrán verse, saborearse, olerse, sentirse, disfrutarse...

31 El voluntario recibe la formación requerida, se prepara como es debido, reza y se concentra para realizar una tarea en la que sus brazos y su corazón le conducirán hasta donde él pueda llegar.

32 En el dialecto bigurdan de la zona de la Bigorre, Aquéro significa “esto, eso" y en francés: "cela”. Bernardita, al principio, cuando tenía que transmitir los mensajes y no sabía quien era la persona con la que hablaba, utilizaba esta palabra para referirse a la Virgen. 


\subsection{LOURDES COMO CENTRO DE TURISMO.}

Lourdes cuenta con 15000 habitantes. Este lugar santo gracias a Bernardita y a la que ella siempre ha considerado su madre, La Virgen María, la Inmaculada Concepción, es un centro mariano en el que se respira un alto grado de espiritualidad. Quizá este clima que es único, atraiga y sorprenda al turista y visitante, al peregrino y creyente, incluso al escéptico no dejando a nadie indiferente. Sin duda alguna el momento de mayor afluencia de personas se produce del 11 al 16 de agosto con motivo de la Peregrinación Nacional ${ }^{33}$.

Este clima espiritual por si solo basta en un centro de peregrinación mariano como éste, pero es inevitable que la persona que aquí acude quiera llevarse un recuerdo, este gesto natural, normal y comprensible ha permitido el desarrollo de otro tipo de clima, el comercial y turístico. En las tiendas de la ciudad convive el rosario con el abrigo de lana, la navaja típica de la región con el cuadro religioso. El lado más comer-

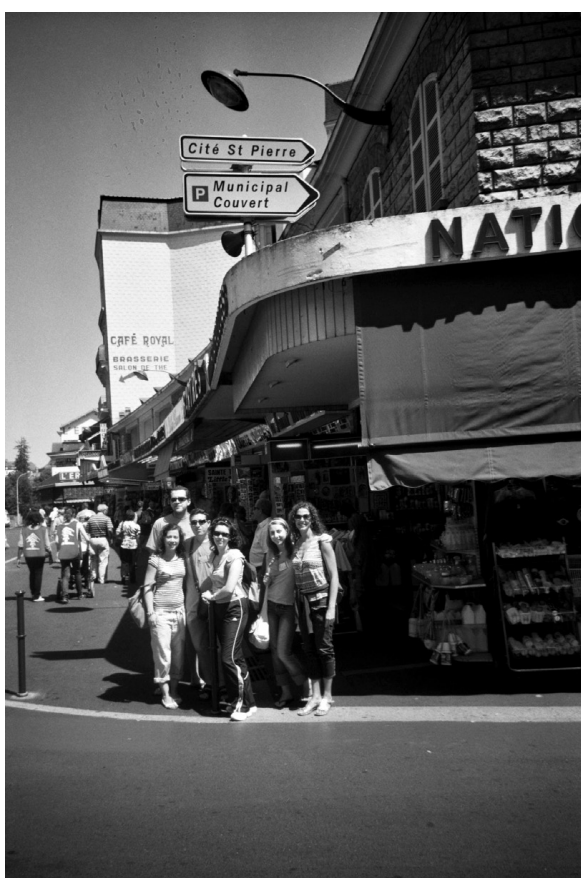

Foto 13. Grupo de Jóvenes Voluntarios Universitarios en una céntrica calle de la ciudad de Lourdes. cial y bullicioso de la calle, el mundo de las tiendas, librerías y cafeterías puede gustar, atraer o por el contrario puede repeler y ser criticado de forma brutal.

Turismo y espiritualidad no están reñidos, en Lourdes estos mundos dispares conviven de una forma regulada. Al final, voluntarios, peregrinos, turistas y visitantes venidos de todos los rincones del mundo acuden a las tiendas para comprar un recuerdo ya sea religioso o no de este lugar. De regreso a casa, este detalle será una prolongación de Lourdes, un reflejo de que se ha estado aquí o de que alguien ha pensado en nosotros, como ocurre con la luz de la vela allí depositada, e incluso con la propia peregrinación.

Clima espiritual y turístico pero también cultural y deportivo. La montaña convive con la gruta, los paseos con los rezos, las visitas con las oraciones, el café y "la crêpe" con la Misa. Y es que en los ratos libres, se bebe un "Panaché" o una "Orangi$n a$ " incluso un "Madiran" y en el menú se pide "Canard" y por la tarde se puede ir al

33 En 2010, la 137 edición ha reunido como casi siempre a unos 10000 peregrinos que unidos al resto de visitantes festejan la fiesta de la Asunción del 15 de agosto. Cada año, más de cinco millones de peregrinos, visitantes o turistas pasan por Lourdes. 
cine, teatro, museo o a ver una exposición o un documental, incluso ir de excursión a la montaña. Todos estos "mundos" conviven en Lourdes y "bien vividos" son muy enriquecedores.

En ocasiones, se dejan LOS SANTUARIOS sin saber que los alrededores poseen unos paisajes maravillosos, incluso se deja la Ciudad de Lourdes sin saber que guarda rincones espléndidos para el descanso, la reflexión, la distracción y formación complementaria de voluntarios, peregrinos, visitantes y turistas. El voluntario que ha terminado su tarea y dispone de media tarde o de un día libre, y el visitante, turista o peregrino que lo desee, puede visitar la ciudad y sus alrededores. Las propuestas son diferentes: Pasear por las montañas que bordean el Río Gave durante una mañana, una tarde o un día, subir a la cumbre del Béout, visitar el famoso Pic du Jer con la posibilidad de coger el funicular, aquí se organizan veladas astronómicas con maravillosas y espectaculares noches de estrellas, no hay que perderse la observación del cielo ni la contemplación del atardecer sobre el Lago de Lourdes. En este Lago, a dos kilómetros de la ciudad, se puede pasear y practicar el remo, la pesca y la navegación deportiva. Lourdes tiene también un campo de golf, bosques y jardines, zonas para picnic, piscina de verano y piscina cubierta.

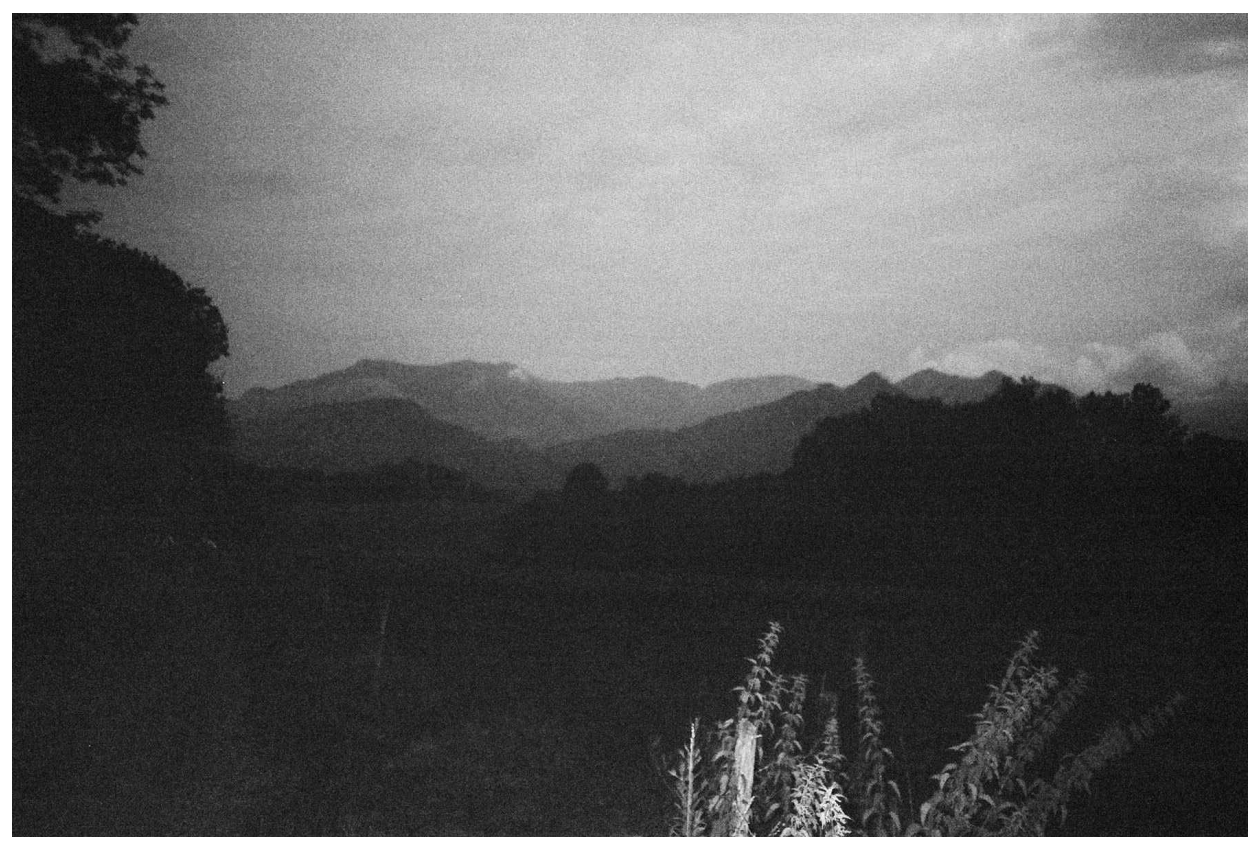

Foto 14. Atardecer en el Valle del Gave.

Este municipio que se encuentra en la Región MEDIODÍA-PIRINEOS en el Departamento de los ALTOS PIRINEOS y bañada por el Río Gave, tiene una altitud de 400 metros y en ella finaliza el Valle de Lavedan. La ciudad muy bien equipada, goza de campings y tiene más de 400 hoteles. Desde el Castillo de esta ciudad hotelera 
puede admirarse el Valle del Gave o de Lavedan y obtenerse una panorámica excepcional de LOS SANTUARIOS. Por su situación estratégica, el Castillo se convirtió en puesto militar y en cárcel a finales del siglo XVII. En su interior puede visitarse el Museo Pirenaico con el arte y la tradición de la región así como exposiciones ${ }^{34}$.

En el Palacio de Congresos de Lourdes hay exposiciones de fotografía. Y en el interior de LOS SANTUARIOS hay exposiciones de pinturas realizadas por los enfermos y minusválidos.

Numerosos son los museos de la ciudad: Notre-Dame, Gemmail, Museo de cera de Grévin, entre otros. La historia de la Medalla Milagrosa es narrada en todas las lenguas en el centro de Diaporamas de Lourdes. En el cementerio de la calle de Langelle se encuentra la sepultura del Capuchino G.Filon que falleció estando de peregrino en Lourdes. Puede visitarse la Iglesia Parroquial de Lourdes dónde se encuentra la Pila en la que Bernadette fue bautizada y una Cripta con una preciosa escultura de la Virgen de Montserrat.

El cine y el teatro se dan cita en Lourdes, durante el verano la puesta en escena y al aire libre de diferentes obras en Los Jardines del Ayuntamiento son de un enorme interés cultural ${ }^{35}$. La ciudad cuenta con librerías muy completas, sin olvidar la de

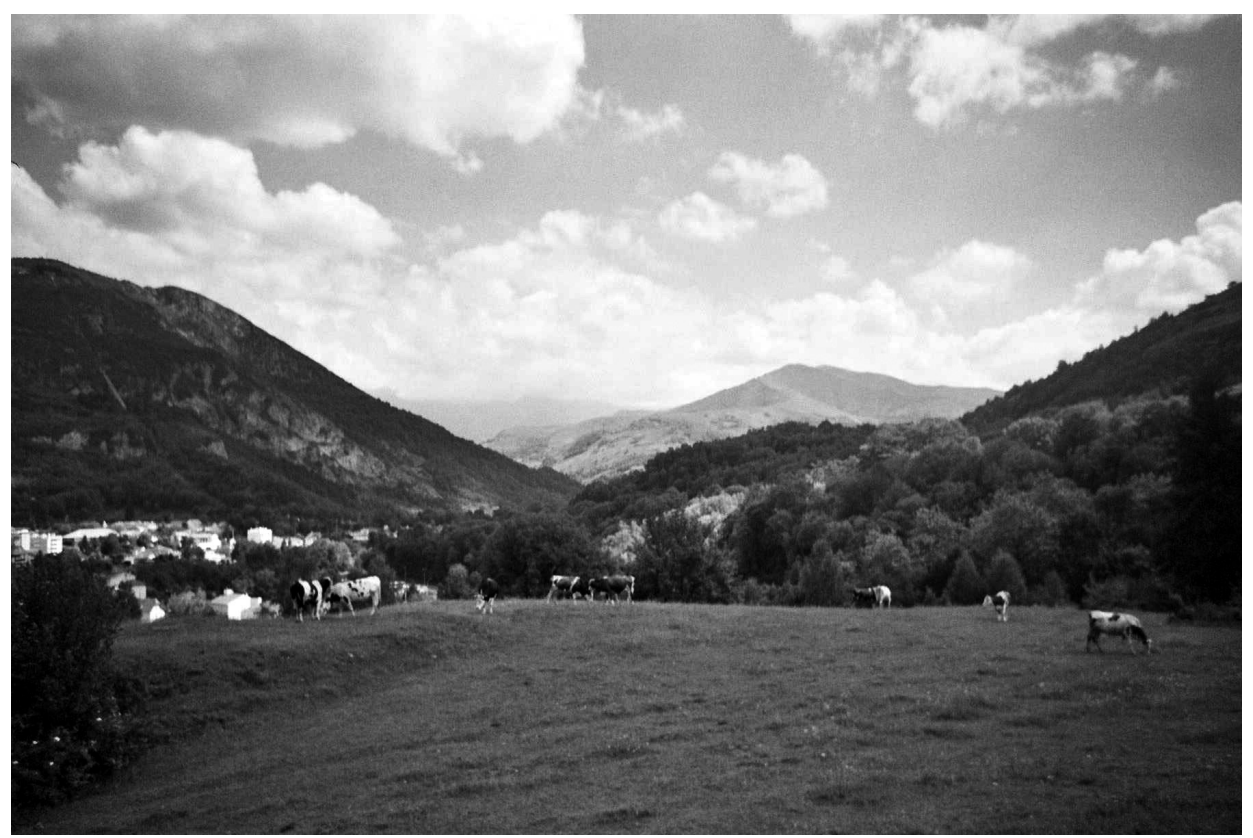

Foto 15. Vista del Pic du Jer y funicular a la izquierda.

34 Este año ha habido una muestra del viajero, explorador, escritor y amante del Pirineo Henry Russell con el título: "HENRY RUSSELL Y LA MAGIA DE LA MONTAÑA."

35 En julio pudo verse "CHAT EN POCHE" con Michel Galabru, una obra del autor Georges FEYDEAU. 
LOS SANTUARIOS, en ellas se consiguen libros interesantes de literatura y mística, religión y arte, historia..., música sacra y útiles postales. Por último resaltar el mercadillo en el centro de la ciudad y el trenecito que recorre Lourdes.

Y es que Lourdes propone excursiones de medio día o de un día, más allá de la ciudad. Visitas de grutas y picos, termas y abadías, refugios, lagos y praderas, degustaciones y catas, eventos deportivos y culturales dan a conocer el Departamento de LOS ALTOS PIRINEOS y sus VALLES ${ }^{36}$.

Los lugares que pueden visitarse desde Lourdes son entre otros, el Circo de Gavarnie que cada año propone representaciones teatrales diversas, Cauterets- Pont d'Espagne $e^{37}$ y su cascada, Bagnères-de Louchon y el Gouffre d'Esparros. Los Lagos de Gaube y Artouste y los lagos de los valles d'Aure y de Louron. Las Grutas de Labastide, Bétharram, Médous y de Gargas. La Abadía de L'Escadieu en la Ruta Europea de las Abadías Cistercienses se enmarca dentro de un itinerario cultural proyectado por el Consejo de Europa. La Asociación de los Amigos del Parque Nacional de los Pirineos proponen rutas de senderismo y subidas a refugios como el de Ayous $^{38}$. La colline aux marmottes en Argelès-Gazost muy cerca de Lourdes, Le Donjon des Aigles y Le Parc aquatique, son lugares ideales para niños y mayores.

Entorno privilegiado para los amantes de la naturaleza pero también para los amantes de balnearios y de aguas termales ${ }^{39}$. Para los amantes de la micología que pueden recoger esplendidos boletos en todo el bosque pirenaico, incluso en verano. Y para los amantes de la cultura y los cinéfilos ${ }^{40}$.

\footnotetext{
$36 \mathrm{Al}$ Oeste, el VALLE DE LAVEDAN o de la cuenca del río GAVE formado por Lourdes y Argelès Gazost. En el Centro, el VALLE DE CAMPAN formado por el Pic du Midi, el Pico del Tourmalet y los Macizos de Néouvielle y Arbizon. Al Este, el VALLE DEL NESTE y ARREAU, y el VALLE DE AURE Y LOURON.

37 Página web: www.cauterets.com

$38 \mathrm{La}$ Asociación propone también rutas culturales por senderos que unen el Océano Atlántico con el Mar Mediterráneo y que permiten descubrir los mundos celta y romano como en Saint-Laurent de Neste Página Web: www.neste-nistos.com.

39 En las montañas pirenaicas, las aguas termales de Bagnères de Bigorre son muy apreciadas, sin olvidar los centros termales lúdicos de Capvern-Les-Bains y de Barèges.

40 Los cinéfilos y amantes del teatro y de la cultura pirenaica pueden ir a Loudenville, un espacio cinematográfico y museográfico algo anacrónico. En el interior de una antigua granja restaurada pueden descubrirse las novedades del séptimo arte. En el interior del museo de este espacio llamado El Arixo puede contemplarse el patrimonio artístico del Valle. Igualmente pueden visitarse Exposiciones artísticas en Argelès-Gazost muy cerca de Lourdes y en el Valle del Gave pueden verse creaciones en vidrio, pintura, escultura y cerámica. La Abadía cisterciense de l'Escadieu ofrece espectáculos de danza, conciertos, teatros y conferencias. Uno de los castillos-fortalezas que ocupan el territorio del patrimonio pirenáico más antiguos es el Castillo de Moulor en el Valle de Aure-louron que fue construido en el siglo XII.
} 
Estos Valles son también un lugar privilegiado para los amantes del deporte, de la aventura ${ }^{41}$, para alpinistas y ciclistas ${ }^{42}$, para los amantes de la pesca ${ }^{43}$, de la nieve ${ }^{44}$, del golf, fútbol y rugby. Todos pueden darse cita en los ALTOS PIRINEOS y vivir, a la vez, veladas de degustación, de gastronomía ${ }^{45}$, música ${ }^{46}$, y de cata de vinos en los Castillos Medievales de sus Valles.

Para quienes deseen vivir su lado espiritual fuera de LOS SANTUARIOS de Lourdes pueden acudir a las Iglesias que se encuentran en los Valles. Destacamos la iglesia de Luz-saint-sauveur en el VALLE DEL GAVE o la de Nuestra señora de las nieves en Gavarnie. En el VALLE DE AURE-LOURON, las pinturas murales en la Iglesia de Jézeau permiten descubrir la iconografía medieval. Los conciertos y cantos de los Pirineos en la Iglesia de Saint-Lary son muy apreciados. En el pueblecito Cadeilhan-trachère, desde la Capilla de Nuestra Señora de la Piedad hasta Saint-Missolin puede seguirse un trecho del Camino de Santiago ${ }^{47}$. Puede visitarse La Capilla de los Templarios en el pueblo de Arreau y finalmente la Basílica de Saint-Bertrand de Comminges excepcional por su arquitectura galo-romana y la Basílica Saint-justde-Valcabrère del siglo XII.

41 La estación de ski de Peyragudes en verano propone actividades para toda la familia: senderismo, parapente, escalada, pesca, rando quad, rando poney, rafting, canyoning.

Para los amantes de la aventura pueden realizarse marchas y diversas actividades desde los refugios. Hay once refugios y siete son de altura, pueden hacerse reservas si se quieren descubrir detalles de la montaña pirenaica. Web: www.clubalpim.com

Todos los Valles tienen guías y monitores que ayudan al turista, visitante o deportista a conocer la naturaleza de las montañas del Pirineo. También puede vivirse la aventura y el riesgo con el descenso del río Garona a su paso por Barbazan. Para vivir la aventura dentro de la montaña pueden visitarse las Minas de Vielle-Aure muy cerca de Saint-Lary en el VALLE D'AURE.

Una nueva disciplina de moto bastante espectacular se viene desarrollando en el Pic du midi, se trata del Openfree.

42 En el Valle del Gave, la carrera de coches en Cauterets se da cita todos los veranos, y en el Valle del ALTOADOUR se organiza una vuelta ciclista que pasa por el Tourmalet y que reúne a ciclistas y aficionados. 43 Sin olvidar la pesca, en casi todos los pueblos, los concursos de pesca son casi tan frecuentes como los de petanca, diferentes municipalidades organizan estos concursos, pueden destacarse el organizado por Campan en Payolle, y el de Beaudean.

44En los inviernos pirenaicos la nieve espera a los esquiadores en estaciones como Saint-lary, Le Hautacam, Barèges, La Mongie, Cauterets, Luz-Ardiden, Gavarnie-les-espéciers, y Piau-engaly entre otras. 45 Destacar la gastronomía y el vino de la tierra del Valle del Adour con la fiesta del vino en las localidades de Madiran y de Crouseilles.

46El festival de música de Saint Savin. Página web: www.festivalsaintsavin.com

47 Son distintas las rutas que cruzan el Suroeste francés. Los departamentos de los ALTOS PIRINEOS y PIRINEOS ATLÁNTICOS son atravesados por 5 rutas diferentes. La que pasa por Carcassonne, Foix, St. Gaudens, Montréjeau, Lourdes, St Pé de Bigorre, Oleron-Ste-Marie, Ste Engrace conduce a Sangüesa en España. Las otras rutas son LA TOLOSONA que pasa también por Oleron-Ste-Marie, muy cerca de Lourdes, la VÍA PODIENSIS, la VÍA LEMOVICENSIS y la TURONENSIS. 


\section{CONCLUSIONES. LOURDES COMO CENTRO DE PEREGRINACIÓN, VOLUNTARIADO Y TURISMO.}

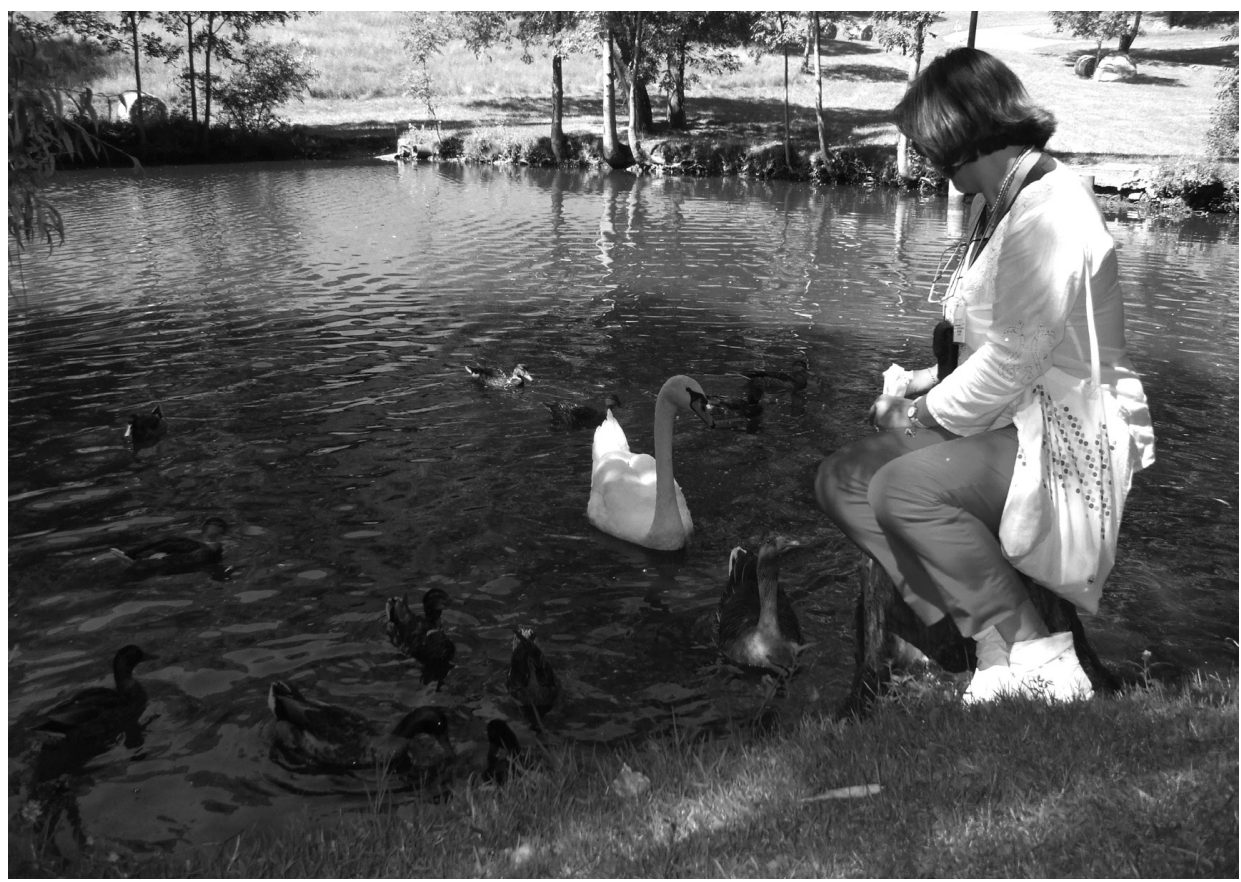

Foto 16. Voluntaria en el Lago de La Cité San Pedro en Lourdes.

Voluntario, peregrino o turista en LOS SANTUARIOS, en LOURDES o en LOS VALLES, y de peregrinación, de oración, de tiendas o de excursión, la armonía del alma se refleja en la armonía del paisaje pirenaico en forma de Basílica, Pico o Lago.

Naturaleza y espiritualidad no es una combinación novedosa. Monasterios, Iglesias, Abadías y Criptas son un testimonio de ello. Numerosas son las edificaciones ubicadas en lugares altos de montañas, valles tranquilos, frondosos bosques y vastos pinares para ver, tocar y sentir la obra creada por Dios con los ojos del cuerpo y del alma. Ir al campo, subir a una cima, bordear un pico, recorrer un camino, ir en procesión, son acciones que expresan el deseo de ir al encuentro de la parte espiritual de uno mismo y escuchar sus silencios, gritos o medias palabras.

Un esfuerzo físico que compensa el descanso mental de la persona que busca la paz y el equilibrio en su vida. La sentencia latina de Juvenal conserva todo su peso "Mens sana in corpore sano" cuerpo y mente en equilibrio para que una parte no arrastre a la otra, y para que la vida del alma pueda expresarse "Alma sana en un cuerpo sano." Salud espiritual y salud corporal. 
Esta búsqueda natural del hombre encaminada hacia la naturaleza corre paralela a la buscada en lugares como los Santuarios. Naturaleza y Centros de Peregrinación reconcilian la parte física, mental y espiritual del hombre.

Santiago de Compostela reúne en sus distintos caminos a peregrinos del mundo entero que por motivos diferentes van en busca de ellos mismos, de los demás. Tierra Santa, Loyola, Fátima, Asís son una respuesta a esta búsqueda.

El querido hermano San Francisco de Asís en el siglo XIII pasaba días recorriendo bosques y alabando a Dios en las criaturas, los astros y las plantas. Hablaba de la hermana luna y del hermano sol, de la hermana lluvia. Para él, la flora y la fauna eran un reflejo de la divina creación. Toda la naturaleza le hablaba de Dios. Pero también hablaba de la hermana pobreza, de la hermana humildad. Para Francisco la perfecta alegría coincidía con el mayor desconsuelo, y en el camino recorrido por Bernardita, cada miseria le acercaba a un sueño.

Peregrinación y voluntariado, espiritualidad y naturaleza, cultura y turismo se entienden desde la generosidad y la búsqueda, desde la solidaridad y el encuentro, dando, compartiendo y recibiendo. Lourdes está ahí como una expresión del amor de Dios hacia sus hijos - y a la vez, como expresión del amor de estos hijos hacia los demás.- Todos; servidores y servidos, peregrinos, y visitantes, turistas y curiosos viven esta experiencia y sólo los más osados dejan en las manos de la Madre, como hizo Bernardita, sus sueños.

¡HASTA PRONTO LOURDES!

\section{BIBLIOGRAFÍA}

ARCHIVES SOEURS DE LA CHARITÉ DE NEVERS (2008): Carnet de notes intimes. Nevers, France. 2è edition augmentée.

ARCHIVES SOEURS DE LA CHARITÉ DE NEVERS (1978): Bernadette disait... Nevers, France. Espace Bernadette.

AUSINA, GÉRARD Y PRODOMI, LUIGI: Lourdes. Versión Española. Ediciones Doucet-Lourdes.

RODHAIN, JEAN. PRÊTRE (2005): Lourdes, des fleurs inattendues. Biarritz, NDL Éditions.

Las publicaciones del Servicio Jóvenes cuyos textos han sido escritos por Padres Oblatos de María Inmaculada, y que pueden encontrarse a la entrada del Edificio Forum Centre d'Information en diferentes lenguas:

CHALVET DE RÉCY, YVES Y BERNARD DULLIER: En camino hacia Bartrès. CHALVET DE RÉCY, YVES Y CLAUDE RIBOULET: Conocer el Santuario. CHALVET DE RÉCY, YVES Y BERNARD DULLIER: Tras las huellas de Bernardita. 


\section{MÚSICA EN FRANCÉS ACONSEJADA}

- Algunos discos CD con las canciones francesas más utilizadas en las misas:

1. LES 20 PLUS BEAUX CHANTS POUR PRIER. Collection "Peuple en prière" Studio SM, Paris, 1995.

2. LES PLUS BEAUX CHANTS POUR PRIER. Collection "Liturgies" Studio SM, Paris, 2000.

- Sobre San Francisco de Asis:

3. SAGESSE. Illustration musicale et morceaux choisis de l'oeuvre d'Éloi Leclerc: SAGESSE D'UN PAUVRE.

- Sobre El Hijo Pródigo:

4. LA DANSE DU PARDON, Ghislan Planty.

- Sobre la Virgen María:

5. MARIE DES PYRÉNÉES, David Olaïzola, un Canto Vasco LURDEKO LOREA y el AVE MARIA.

6. RÉJOUIS-TOI, RAYONNEMENT DE JOIE!, Par Sylvie Buisset. Béatitudes Musique.

- Melodías para alabar a Dios:

7. MÉLODIES POUR LOUER DIEU. Collection "Resonances", Paris, 1999 